\title{
The Supercritical Multithermal Fluid Flooding Investigation: Experiments and Numerical Simulation for Deep Offshore Heavy Oil Reservoirs
}

\author{
Xianhong Tan, ${ }^{1,2}$ Wei Zheng $\mathbb{D}^{1,2}$ Taichao Wang, ${ }^{1,2}$ Guojin $\mathrm{Zhu},{ }^{1,2}$ Xiaofei Sun $\mathbb{D}^{1,3}$ \\ and Xiaoyu Li iD 1,3 \\ ${ }^{1}$ State Key Laboratory of Offshore Oil Exploitation, Beijing 100028, China \\ ${ }^{2}$ CNOOC Research Institute Ltd, Beijing 100028, China \\ ${ }^{3}$ China University of Petroleum (East China), School of Petroleum Engineering, Qingdao 266580, China
}

Correspondence should be addressed to Wei Zheng; zhengwei_aswill@163.com

Received 19 January 2021; Accepted 25 May 2021; Published 15 June 2021

Academic Editor: Basim Abu-Jdayil

Copyright ( 2021 Xianhong Tan et al. This is an open access article distributed under the Creative Commons Attribution License, which permits unrestricted use, distribution, and reproduction in any medium, provided the original work is properly cited.

\begin{abstract}
The supercritical multithermal fluids (SCMTF) were developed for deep offshore heavy oil reservoirs. However, its EOR mechanisms are still unclear, and its numerical simulation method is deficient. In this study, a series of sandpack flooding experiments were first performed to investigate the viability of SCMTF flooding. Then, a novel numerical model for SCMTF flooding was developed based on the experimental results to characterize the flooding processes and to study the effects of injection parameters on oil recovery on a lab scale. Finally, the performance of SCMTF flooding in a practical deep offshore oil field was evaluated through simulation. The experiment results show that the SCMTF flooding gave the highest oil recovery of $80.89 \%$, which was $29.60 \%$ higher than that of the steam flooding and $11.09 \%$ higher than that of SCW flooding. The history matching process illustrated that the average errors of $3.24 \%$ in oil recovery and of $4.33 \%$ in pressure difference confirm that the developed numerical model can precisely simulate the dynamic of SCMTF flooding. Increases in temperature, pressure, and the mole ratio of $\mathrm{scN}_{2}$ and $\mathrm{scCO}_{2}$ mixture to SCW benefit the heavy oil production. However, too much increase in temperature resulted in formation damage. In addition, an excess of sc $\mathrm{N}_{2}$ and $\mathrm{scCO}_{2}$ contributed to an early SCMTF breakthrough. The field-scale simulation indicated that compared to steam flooding, the SCMTF flooding increased cumulative oil production by $27122 \mathrm{~m}^{3}$ due to higher reservoir temperature, expanded heating area, and lower oil viscosity, suggesting that the SCMTF flooding is feasible in enhancing offshore heavy oil recovery.
\end{abstract}

\section{Introduction}

The decline of light oil production and the exhaustion of onshore heavy oil resources lead to an increasing demand of offshore heavy oil $[1,2]$. Due to high but the temperature-dependent viscosity, the development regimes of offshore heavy oil, especially for oil with viscosity exceeding $350 \mathrm{mPa} \cdot \mathrm{s}$, can only be effectively extracted by thermal methods $[3,4]$.

The steam injection is the most successful and worldwide thermal method and has been applied in many offshore oil fields, such as Bohai field in China and Bressay field and
Bentley field in the UK $[5,6]$. However, for deep offshore heavy oil reservoirs, injected steam has low quality, leading to an inefficient heavy oil production [6]. Therefore, there is an urgent need of a new effective thermal agent for deep offshore heavy oil.

Recently, the supercritical multithermal fluids (SCMTF), which is composed of supercritical water (SCW), $\mathrm{scN}_{2}$, and $\mathrm{scCO}_{2}$, were produced by a newly designed generator to develop deep offshore heavy oil [7]. The generation of SCMTF is realized by the gasification of produced waste water and combustion of gasification product in SCW [8]. In contrast of steam, SCMTF 


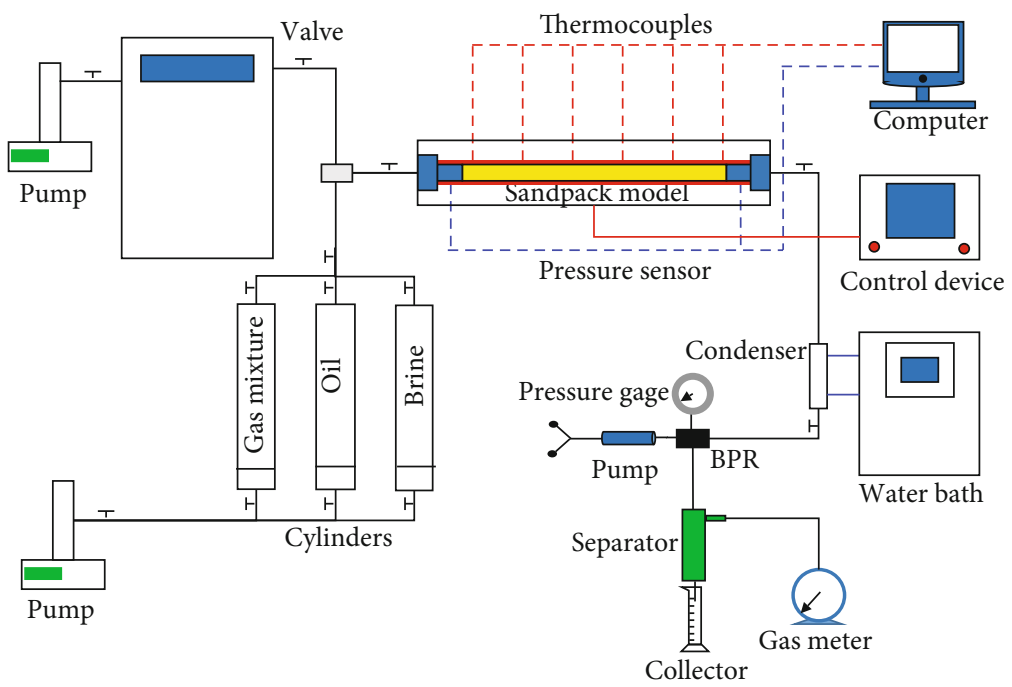

Figure 1: Schematic diagram of the experimental apparatus.

has the following advantages: (1) the produced waste water is utilized as feedstock for SCMTF generation, which reduces the disposal cost of waste water, and the fuel cost for steam generation; (2) the SCMTF generator occupies small areas of land, which is more convenient than the large-scale steam generator considering the narrow space of offshore platforms; and (3) the temperature and dryness fraction of SCMTF is much higher than that of steam. Therefore, it is inferred that the SCMTF is superior to steam in enhancing deep offshore heavy oil recovery.

As a special thermodynamic state of water (temperature $>374^{\circ} \mathrm{C}$ and pressure $>22.1 \mathrm{MPa}$ ), SCW can behave as an organic solvent with a good solubility of hydrocarbon $[9,10]$ and substantially increase oil mobility by upgrading [11-13]. Inspired by this favourable feature, Zhao et al. studied the viability of SCW flooding on heavy oil recovery by experiments and confirmed that SCW flooding is capable of enhancing heavy oil recovery [14]. They also proposed that the main EOR mechanisms of SCW flooding were miscible flooding, heavy oil upgrading, and override suppression [15, 16]. Yin et al. reported the implementation of cyclic SCW stimulation in Tuha oil field, China, which sharply increased the oil production rate from $1.9 \mathrm{t} / \mathrm{d}$ to $10 \mathrm{t} / \mathrm{d}$ [17]. Yang noted that the SCW injection was put into practical use in Lukeqin oil field and the oil production rate was hence improved from $2.3 \mathrm{t} / \mathrm{d}$ to $12 \mathrm{t} / \mathrm{d}$ [18]. Liu et al. described an application of cyclic SCW stimulation in Liaohe oilfield, increasing cyclic oil production by 8524t [19]. Zhang et al. reported the cyclic SCW stimulation application in Shengli oilfield, resulting in a $48 \%$ increment in oil production [20]. These investigations indicated that the SCW injection can effectively produce heavy oil from deep reservoirs.

In addition, previous literatures indicated that the efficiency of thermal methods can be improved by utilizing noncondensable gases such as $\mathrm{CO}_{2}, \mathrm{~N}_{2}$, and flue gas. Wang et al. assessed the performance of $\mathrm{CO}_{2}$-assisted

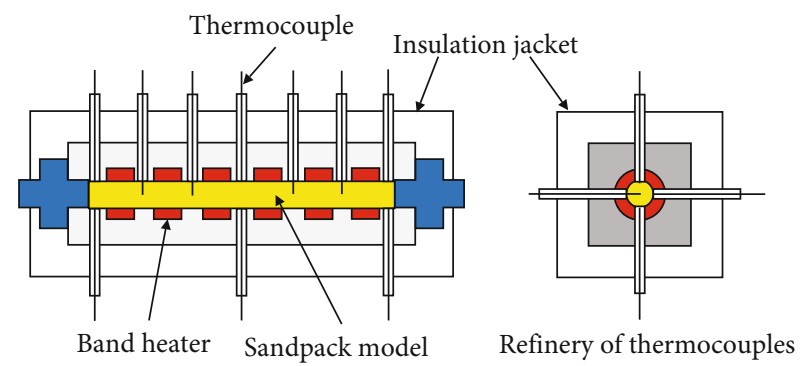

FIgURE 2: The detailed structure of the sandpack.

TABLE 1: Experimental conditions.

\begin{tabular}{lccc}
\hline Experiment No. & 1 & 2 & 3 \\
\hline Porosity (\%) & 25.34 & 24.13 & 25.66 \\
Permeability (mD) & 1130 & 1189 & 1210 \\
Initial oil saturation (\%) & 93.4 & 94.67 & 93.11 \\
Injection rate (ml/min) & 10 & 10 & 10 \\
Injection pressure $(\mathrm{MPa})$ & 10 & 23 & 23 \\
Injection temperature $\left({ }^{\circ} \mathrm{C}\right)$ & 320 & 380 & 380 \\
Injection fluids & Steam & SCW & SCMTF \\
\hline
\end{tabular}

SAGD (Steam Assisted Gravity Drainage) process by experiments and found that $\mathrm{CO}_{2}$ could enhance oil recovery through viscosity reduction and oil swelling at high temperatures [21]. Li et al. demonstrated that during steam flooding, the addition of flue gas could increase heavy oil recovery by extracting heavy oil and reducing interfacial tension [22]. Yuan et al. suggested that the presence of $\mathrm{N}_{2}$ could maintain the formation pressure and expand the steam chamber, which is in favour of heavy oil recovery [23].

As a consequence, the investigations mentioned above suggests that SCMTF, which consists of SCW, $\mathrm{scN}_{2}$, and $\mathrm{scCO}_{2}$, are a promising injection agent for deep offshore heavy oil. However, few researches have investigated the 


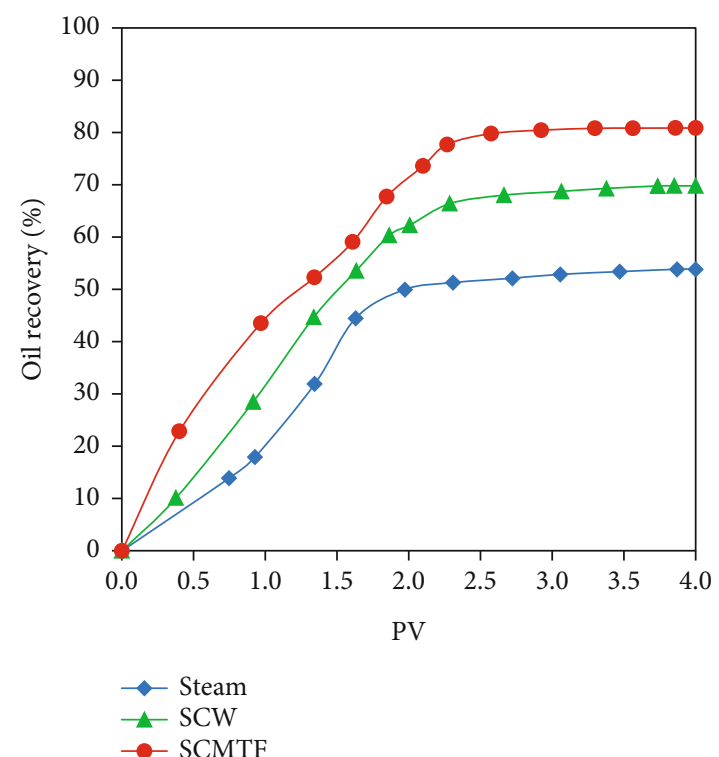

(a)

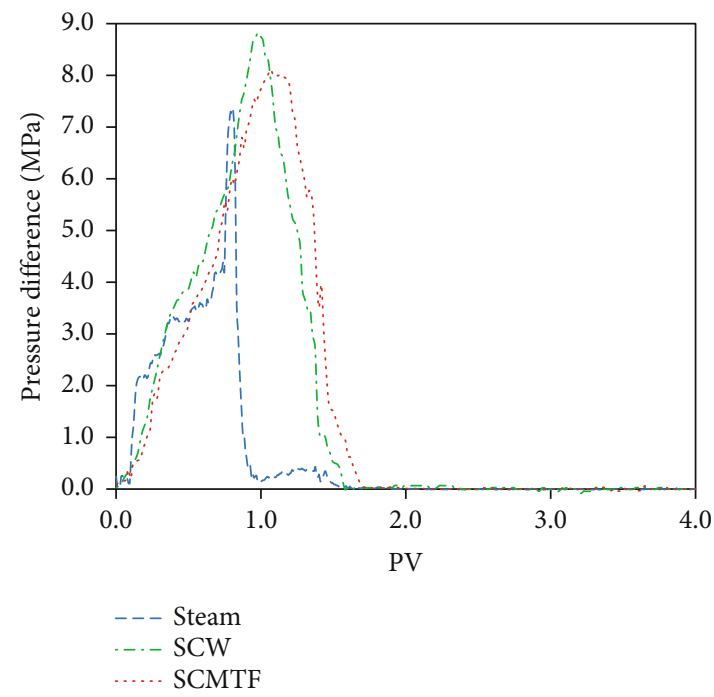

(c)

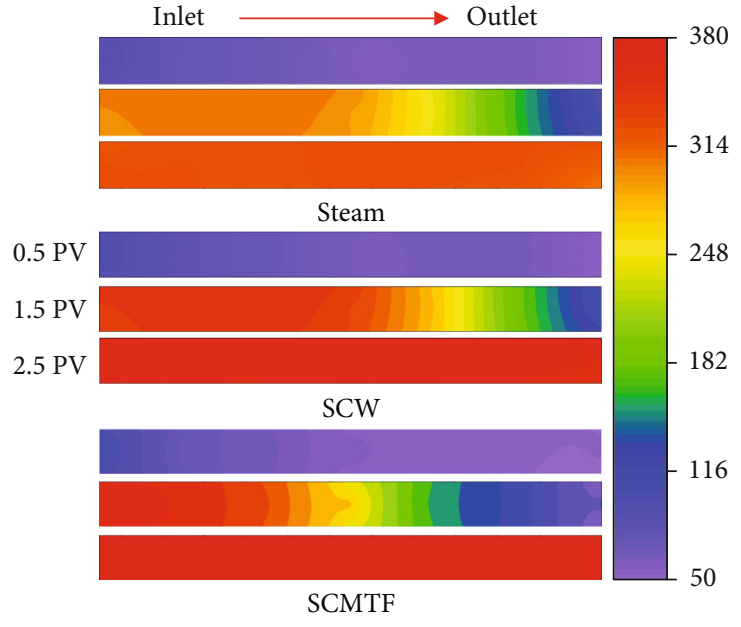

(b)

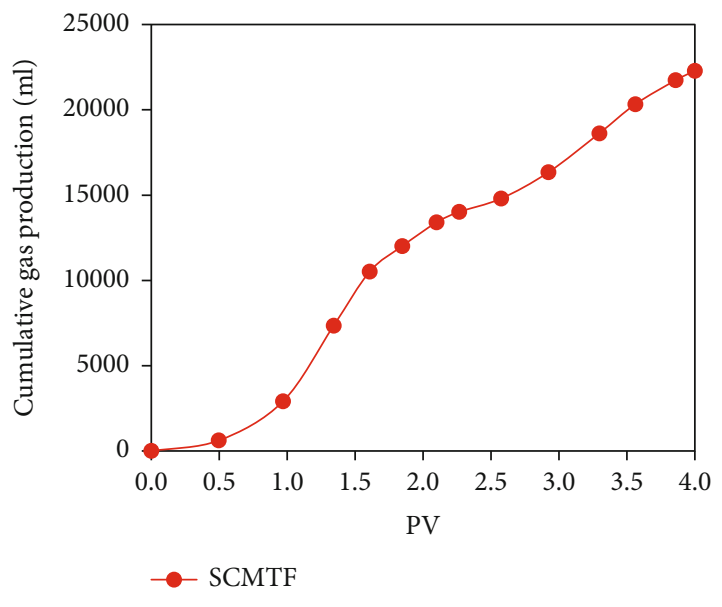

(d)

FIGURE 3: Experimental results of steam, SCW, and SCMTF flooding: (a) oil recovery; (b) temperature distributions; (c) pressure difference; (d) gas production of experiment 3.

performance of SCMTF flooding on deep offshore heavy oil recovery. Thus, its EOR mechanisms are still unclear. In addition, the numerical simulation method for SCMTF flooding is deficient. Therefore, in this study, a series of sandpack flooding experiments were performed to evaluate the feasibility of SCMTF flooding. Then, a lab-scale numerical simulation model was developed and verified by the experimental results. In addition, the effects of injection temperature, pressure, and the mole ratio of $\mathrm{scN}_{2}$ and $\mathrm{scCO}_{2}$ mixture to SCW on oil recovery were investigated by the developed model. Finally, the verified parameters were applied to a field-scale simulation to assess the feasibility of SCMTF flooding on deep offshore heavy oil recovery.

\section{Experiments}

2.1. Materials. The heavy oil utilized for experiments was obtained from Bohai oil field, China. It had a viscosity of $6230 \mathrm{mPa} \cdot \mathrm{s}\left(\right.$ at $50^{\circ} \mathrm{C}$ ), a density of $977 \mathrm{~kg} / \mathrm{m}^{3}$ (at $50^{\circ} \mathrm{C}$ ), and a molecular weight of $750 \mathrm{~g} / \mathrm{mol}$. The formation water was made with a brine containing $5.0 \mathrm{wt}$. $\% \mathrm{NaCl}$. As the composition of SCMTF, a gas mixture with a mole ratio of $\mathrm{N}_{2}$ to $\mathrm{CO}_{2}=85 \%: 15 \%$ was employed for the experiments. Distilled water was applied for the generation of SCW. Quartz sands were adapted to prepare a reservoir model.

2.2. Experimental Apparatus. The experimental apparatus is exhibited in Figure 1. As illustrated, the setup is mainly 


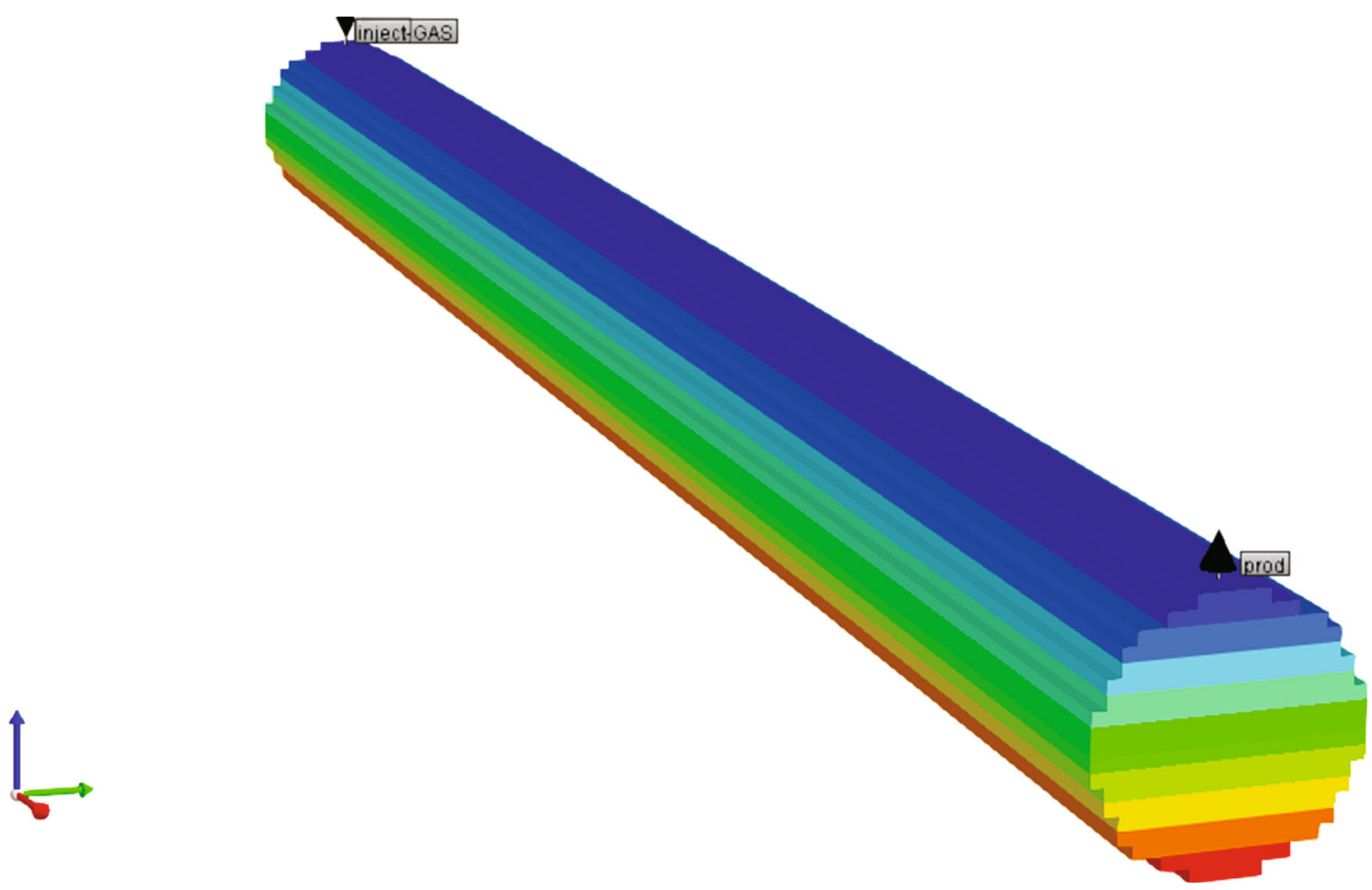

FIgURE 4: The lab-scale model.

composed of four parts: an injection system, a reservoir model, a monitoring system, and a collection system.

The crucial device in the injection system was a newly designed SCW generator (YH Petroleum Machinery Technology Co., Ltd, China), which could generate the SCW at a maximum temperature and pressure of $450^{\circ} \mathrm{C}$ and 35 $\mathrm{MPa}$. A high-pressure pump was employed to inject distilled water into the generator to produce SCW. The rest of the injection system were a high-pressure pump and three cylinders containing gas mixture, heavy oil, and formation water, which were used for injecting experimental fluids.

The reservoir model is a one-dimensional sandpack, illustrated in Figure 2. The sandpack had a diameter of 38 $\mathrm{mm}$ and a length of $480 \mathrm{~mm}$ and can resist $450^{\circ} \mathrm{C}$ and 35 $\mathrm{MPa}$ condition. Six band heaters and an insulation jacket were employed for reducing heat losses and maintaining the reservoir temperature.

The monitoring system was used for temperature control and data acquisition in real time. It consists of thermocouples $\left( \pm 0.2^{\circ} \mathrm{C}\right.$ accuracy within $\left.0-450^{\circ} \mathrm{C}\right)$, pressure sensors $( \pm 87.5 \mathrm{kPa}$ within $0-35 \mathrm{MPa})$, a computer, and a control device. As shown in Figure 2, the thermocouples were uniformly distributed along the sandpack, and at the inlet, the outlet, and the middle of the sandpack, there was a refinery of thermocouples, respectively. At the inlet and outlet of the model, the pressure sensors were arranged to acquire the pressure difference. The data obtained by thermocouples and pressure sensors were recorded by a computer. The control device could control band heaters to heat the sandpack.
In the production system, a backpressure regulator (BPR) was applied for adjusting the model pressure. A condenser and a water bath were used to cool the produced fluids. A separator separated the gas and liquid products, of which the amount was measured by a collector and a gas meter, respectively.

\subsection{Experimental Procedure}

(1) Model preparation

First, the sandpack model was cleaned by kerosene and packed with quartz sands. Second, the sandpack was saturated by the formation water, and the porosity and permeability were determined by a volume method and Darcy's law, respectively. Subsequently, the sandpack was saturated by heavy oil at reservoir conditions, and initial oil saturation was tested.

(2) Flooding procedure

During a typical SCMTF flooding process, SCW and gas mixture were coinjected into the sandpack at $23 \mathrm{MPa}$ and $380^{\circ} \mathrm{C}$. To simulate SCMTF, the mole ratio of the injected $\mathrm{scN}_{2}$ and $\mathrm{scCO}_{2}$ mixture to SCW was maintained at $1: 5$. The oil and gas production, temperature distribution, and pressure difference were recorded in real time. To evaluate the feasibility of SCMTF flooding, 3 sets of experiments (steam, SCW, and SCMTF flooding) were conducted for contrast. The experimental conditions are illustrated in Table 1. 
TABLE 2: The key properties of the model.

\begin{tabular}{|c|c|c|c|}
\hline Parameters & \multicolumn{3}{|c|}{ Values } \\
\hline Initial temperature $\left({ }^{\circ} \mathrm{C}\right)$ & \multicolumn{3}{|c|}{50} \\
\hline Injection temperature $\left({ }^{\circ} \mathrm{C}\right)$ & \multicolumn{3}{|c|}{380} \\
\hline Injection pressure $(\mathrm{MPa})$ & \multicolumn{3}{|c|}{23} \\
\hline Fluid injection rate $(\mathrm{ml} / \mathrm{min})$ & \multicolumn{3}{|c|}{10} \\
\hline Bottom hole pressure of production well $(\mathrm{MPa})$ & \multicolumn{3}{|c|}{23} \\
\hline Rock thermal conductivity $\left(\mathrm{J} /\left(\mathrm{m}^{3} \cdot \mathrm{d} \cdot{ }^{\circ} \mathrm{C}\right)\right)$ & \multicolumn{3}{|c|}{$1.496 \times 10^{5}$} \\
\hline Rock heat capacity $\left(\mathrm{J} /\left(\mathrm{m}^{3} \cdot{ }^{\circ} \mathrm{C}\right)\right)$ & \multicolumn{3}{|c|}{$2.607 \times 10^{6}$} \\
\hline Water phase thermal conductivity $\left(\mathrm{J} /\left(\mathrm{m}^{3} \cdot \mathrm{d} \cdot{ }^{\circ} \mathrm{C}\right)\right)$ & \multicolumn{3}{|c|}{$5.35 \times 10^{4}$} \\
\hline Oil phase thermal conductivity $\left(\mathrm{J} /\left(\mathrm{m}^{3} \cdot \mathrm{d} \cdot{ }^{\circ} \mathrm{C}\right)\right)$ & \multicolumn{3}{|c|}{$1.15 \times 10^{4}$} \\
\hline \multirow[t]{5}{*}{ Gas phase thermal conductivity $\left(\mathrm{J} /\left(\mathrm{m}^{3} \cdot \mathrm{d} \cdot{ }^{\circ} \mathrm{C}\right)\right)$} & \multicolumn{3}{|c|}{1900} \\
\hline & $S_{\mathrm{w}}$ & $K_{\mathrm{rw}}$ & $K_{\text {ro }}$ \\
\hline & 0.283 & 0 & 1 \\
\hline & 0.323 & 0.00002 & 0.7728 \\
\hline & 0.34 & 0.0002 & 0.6624 \\
\hline \multirow{10}{*}{ Oil-water relative permeability } & 0.36 & 0.0005 & 0.5544 \\
\hline & 0.38 & 0.0012 & 0.4491 \\
\hline & 0.4 & 0.0023 & 0.3471 \\
\hline & 0.486 & 0.0161 & 0.1 \\
\hline & 0.546 & 0.0331 & 0 \\
\hline & 1 & 1 & 0 \\
\hline & $S_{\mathrm{L}}$ & $K_{\mathrm{rg}}$ & $K_{\text {rog }}$ \\
\hline & 0.5867 & 0.204 & 0 \\
\hline & 0.623 & 0.15 & 0.01 \\
\hline & 0.749 & 0.045 & 0.076 \\
\hline \multirow[t]{5}{*}{ Gas-liquid relative permeability } & 0.825 & 0.022 & 0.168 \\
\hline & 0.913 & 0.008 & 0.4121 \\
\hline & 0.944 & 0.006 & 0.5742 \\
\hline & 0.972 & 0.0059 & 0.7696 \\
\hline & 1 & 0 & 1 \\
\hline
\end{tabular}

2.4. Experimental Results. The experimental results of the three experiments are shown in Figure 3. As shown in Figure 3(a), the SCMTF flooding can give the best oil production performance of $80.89 \%$ oil recovery, which is $29.60 \%$ higher than that of the steam flooding and $11.09 \%$ higher than that of the SCW flooding, suggesting that the SCMTF flooding is capable of enhancing deep offshore heavy oil recovery.

The role of SCW during SCMTF flooding can be determined by the comparison of experiments 1 and 2 . As can be seen in Figure 3, in contrast to steam flooding, the SCW flooding resulted in an $18.51 \%$ increase in oil recovery (Figure 3(a)). The better oil production performance of SCW flooding should be ascribed to the following reasons: (1) in comparison to steam flooding, the heat front of SCW was uniform (Figure 3(b)), and high pressure difference period was longer (Figure 3(c)), indicating that the override phenomenon of SCW flooding is weak, and (2) the heavy oil upgrading in SCW can substantially increase oil mobility in contrast of that in steam, as described in a previous study [24].

A comparison of the results of experiments 2 and 3 indicated that the addition of $\mathrm{scN}_{2}$ and $\mathrm{scCO}_{2}$ mixture could further improve oil recovery (Figure 3(a)). In addition, the SCMTF flooding heat front advanced more slowly (Figure 3(b)), and the high pressure difference period was longer in comparison to SCW flooding (Figure 3(c)), suggesting that the presence of $\mathrm{scN}_{2}$ and $\mathrm{scCO}_{2}$ mixture can further suppress thermal agent override. Moreover, the value of pressure difference was lowered, which showed that the oil mobility increased (Figure 3(c)). This should be ascribed to two factors. First, the depressed gas production at the initial flooding stage (Figure 3(d)) suggested the dissolution of $\mathrm{scN}_{2}$ and $\mathrm{scCO}_{2}$ mixture in heavy oil, which could be beneficial for increasing oil mobility [22]. Second, the presence of 


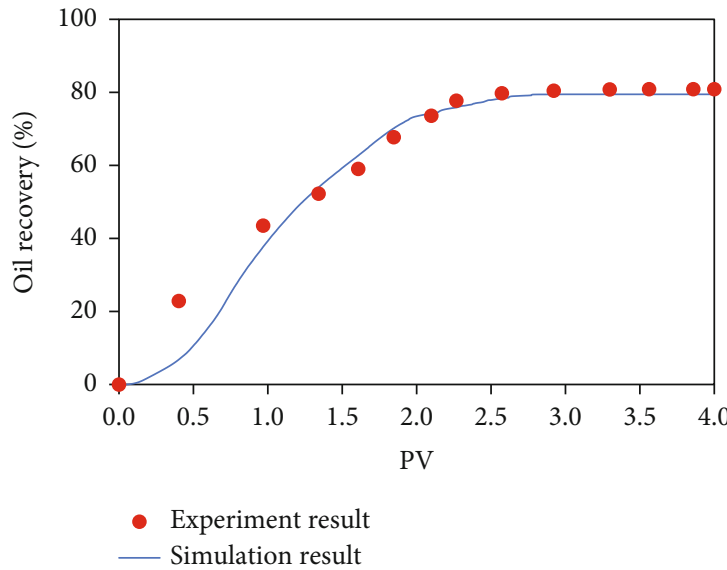

(a)

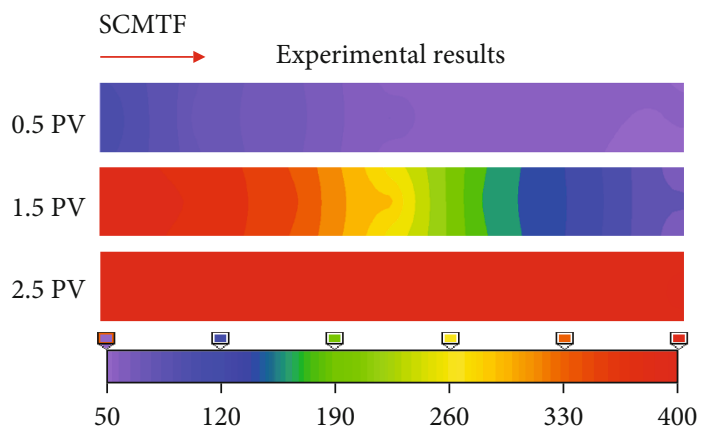

(c)

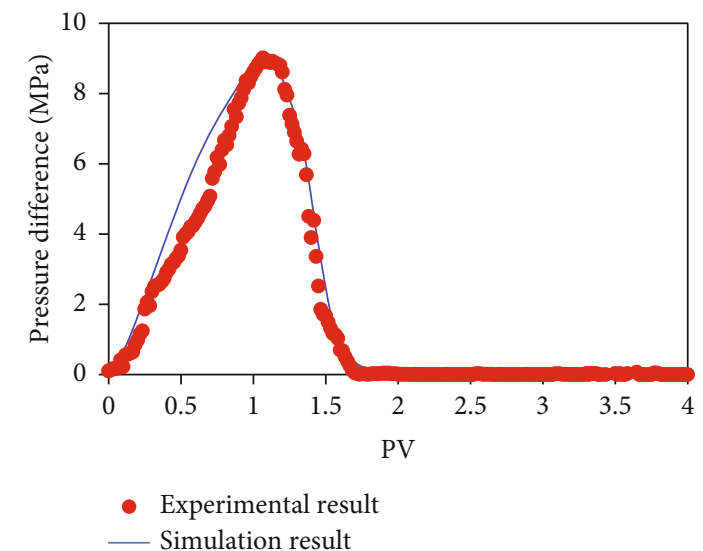

(b)

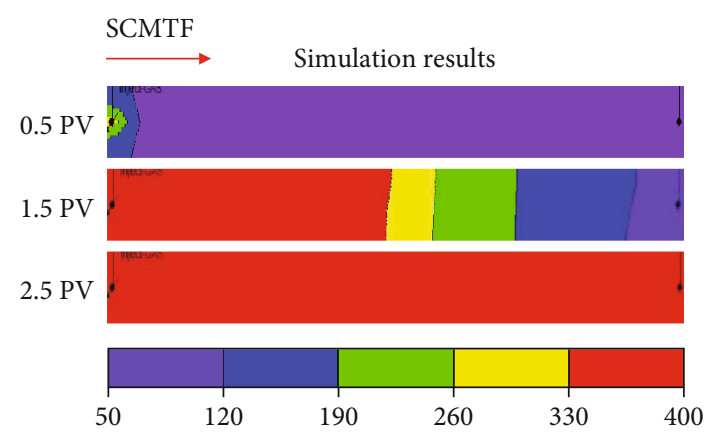

FIGURE 5: Comparison of SCMTF flooding simulation and experimental results: (a) oil recovery; (b) pressure difference; (c) temperature distributions.

$\mathrm{scN}_{2}$ and $\mathrm{scCO}_{2}$ can enhance the heavy oil upgrading [24].

\section{Numerical Simulation}

\subsection{Lab-Scale Numerical Simulation}

3.1.1. Numerical Approach. The flow of SCMTF in porous media is considered to be a complex phenomenon. Therefore, except for the experiments, the development of a detailed numerical method is necessary for clearly depicting SCMTF flooding processes. In this study, a numerical method was developed to simulate SCMTF flooding by using CMG-STARS commercial software. According to the porosity, permeability, initial oil saturation, and operation parameters listed in Table 1, a labscale model was established. As shown in Figure 4, to accurately simulate the experiments, the model was discretized into 17328 grids $(19 \times 48 \times 19$, grid size of 0.2 $\mathrm{cm} \times 1 \mathrm{~cm} \times 0.2 \mathrm{~cm})$.

The previous research revealed that heavy oil upgrading played an important role in oil production during SCMTF injection [24]. According to the oil property tests, product distribution, and gas product analysis presented by Sun et al. [24], the following chemical reaction equa- tion (Equation (1)) was adapted for depicting heavy oil upgrading in SCMTF:

$$
\begin{aligned}
20 \mathrm{~mol} \mathrm{SCW}+ & 0.75 \mathrm{~mol} \mathrm{CO}_{2}+4.25 \mathrm{~mol} \mathrm{~N}_{2}+1 \text { mol heavy oil } \\
& =20 \mathrm{~mol} \text { water }+1.51 \mathrm{~mol} \mathrm{gas} \mathrm{product} \\
+ & 1.71 \mathrm{~mol} \mathrm{light} \mathrm{oil}+0.75 \mathrm{~mol} \mathrm{CO}_{2} \\
+ & 4.25 \mathrm{~mol} \mathrm{~N}_{2}+0.001 \mathrm{~mol} \mathrm{coke}
\end{aligned}
$$

Based on the upgrading reaction and the experimental conditions, the components contained in flooding process were lumped into 4 phases (water, oil, gas, and solid) and 7 types (water, heavy oil, light oil, gas product, $\mathrm{CO}_{2}$, $\mathrm{N}_{2}$, and coke). To reflect $\mathrm{CO}_{2}$ and $\mathrm{N}_{2}$ dissolution in heavy oil, a gas-liquid $K$-value correlation (Equation (2)) was adapted:

$$
K=\left(\frac{\mathrm{kv} 1}{p}+\frac{\mathrm{kv} 2}{p}+\mathrm{kv} 3\right) \times e^{\mathrm{kv} 4 /(T-\mathrm{kv} 5)},
$$

where $K$ denotes the equilibrium constant, $p$ denotes the pressure, and the kv1, kv2, kv3, kv4, and kv5 are the first 


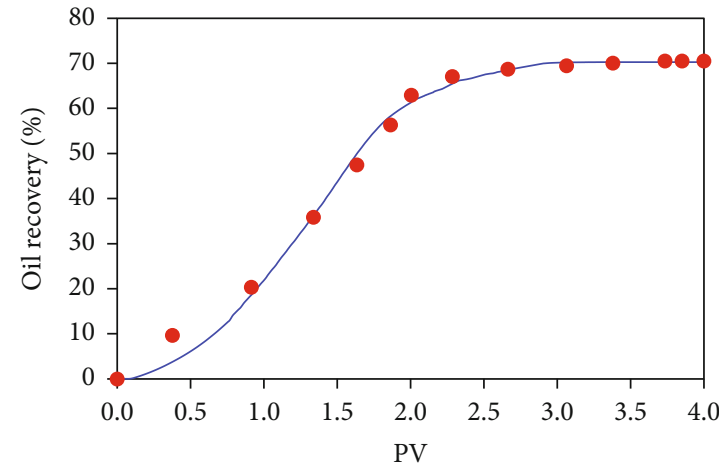

- Experiment result _ Simulation result

(a)

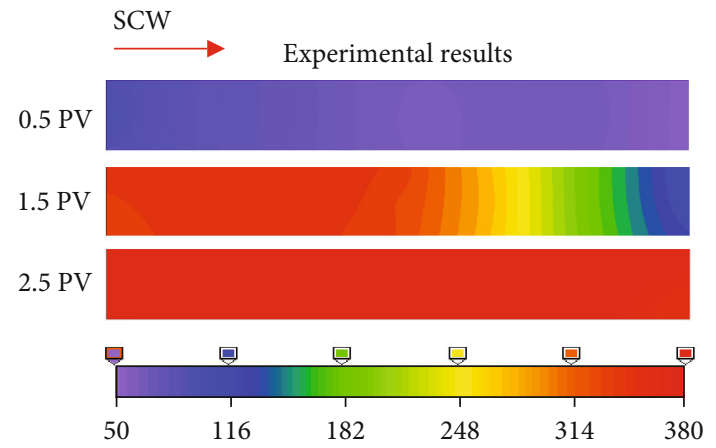

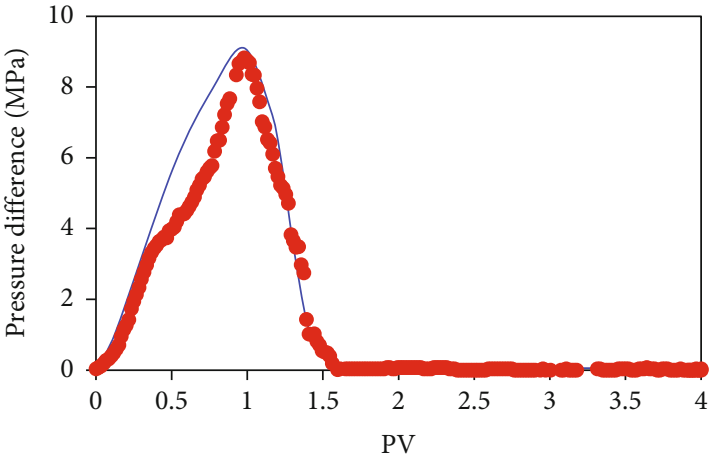

- Experimental result Simulation result

(b)

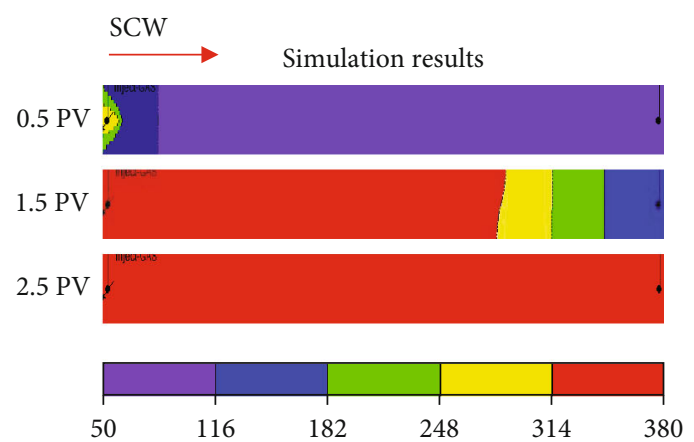

(c)

FIGURE 6: Comparison of simulation and experimental results of SCW flooding: (a) oil recovery; (b) pressure difference; (c) temperature distributions.

to fifth coefficients of $K$-value correlation. The other key properties of the model are listed in Table 2.

3.1.2. History Matching. The kinetic parameters (frequency factor and activation energy) and the relative permeabilities were considered to be of great uncertainties. Therefore, the history matching process was performed through tuning these factors. To precisely simulate SCMTF flooding, the adjustment of kinetic parameters should be limited in a reasonable range. According to the former heavy oil upgrading investigations, the tuning ranges of the frequency factor and activation energy were $3.18 \times 10^{18}-1.04 \times 10^{20} \mathrm{~min}^{-1}$ and $209.45-272.30 \mathrm{~kJ} / \mathrm{mol}$, respectively [25-30].

As illustrated in Figures 5(a) and 5(b), the numerical model could reproduce the oil recovery and pressure difference of the experiment, with average errors of $3.24 \%$ in oil recovery and of $4.33 \%$ in pressure difference, respectively. In addition, the temperature distribution results (Figure 5(c)) indicate that the simulation fits well with the experiment, confirming that the simulation model can precisely simulate the dynamic of SCMTF flooding.

Moreover, the history-matched model was adopted to predict the SCW flooding process, and the experimental and simulation results shown in Figure 6 demonstrate a fair match (average errors of oil recovery is $3.83 \%$ and of pressure difference is $6.37 \%$ ), further confirming the accuracy of the developed model.
3.1.3. The Characterization of SCMTF Flooding. Figure 7 exhibits the calculated SCW, light oil, $\mathrm{scN}_{2}$ and $\mathrm{scCO}_{2}$ mixture, viscosity, oil saturation, and coke distributions during SCMTF flooding. As presented in Figures 7(a) and 7(b), as the SCMTF was injected $0.5 \mathrm{PV}$, the SCW accumulated at the inlet of sandpack model, and the light oil mainly distributed near the inlet. By the fact that the SCW dominate the heavy oil upgrading in SCMTF [24], only the heavy oil near the inlet underwent upgrading process, contributing to the aforementioned phenomena. In addition, $\mathrm{scN}_{2}$ and $\mathrm{scCO}_{2}$ promote more rapidly than SCW (Figure 7(c)), and the shape of low-viscosity area (Figure 7(c)) was similar to the gas distribution. Therefore, the dissolution of gas mixture played a leading role on viscosity reduction at this stage (Figure $7(\mathrm{~d})$ ). In addition, the mobility of the most of heavy oil was still low. Therefore, only a small part of oil was extracted out of the outlet (Figure 7(e)).

With the constant injection of SCMTF, the SCW, $\mathrm{scN}_{2}$, and $\mathrm{scCO}_{2}$ gradually advanced to the outlet of sandpack. At the injection volume of $1.5 \mathrm{PV}$, the SCW migrated to the middle of the model (Figure 7(a)). The enlarged SCW distribution induced the acceleration of heavy crude upgrading, expanding the light oil distribution (Figure 7(b)). The synthesis effects of heavy oil upgrading, $\mathrm{scCO}_{2}$ dissolution, and heating drastically decreased oil viscosity in the whole model (Figure 7(d)), which resulted in the reduction of oil saturation (Figure 7(e)). Notably, due to the buoyancy effect, $\mathrm{scN}_{2}$ and $\mathrm{scCO}_{2}$ mainly distributed at the upper part of the model 


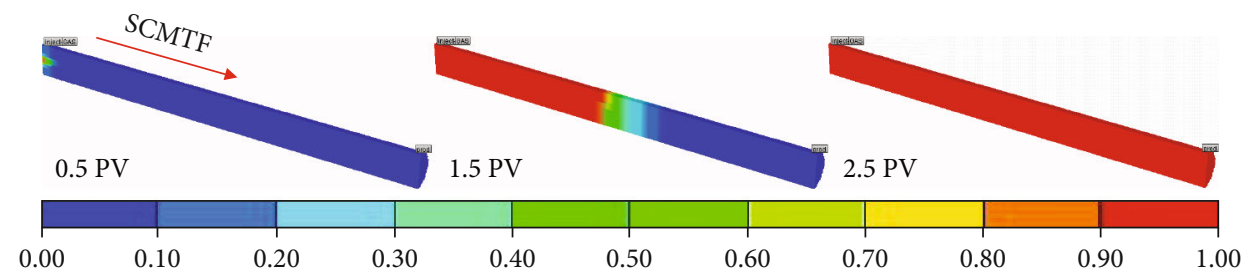

(a)

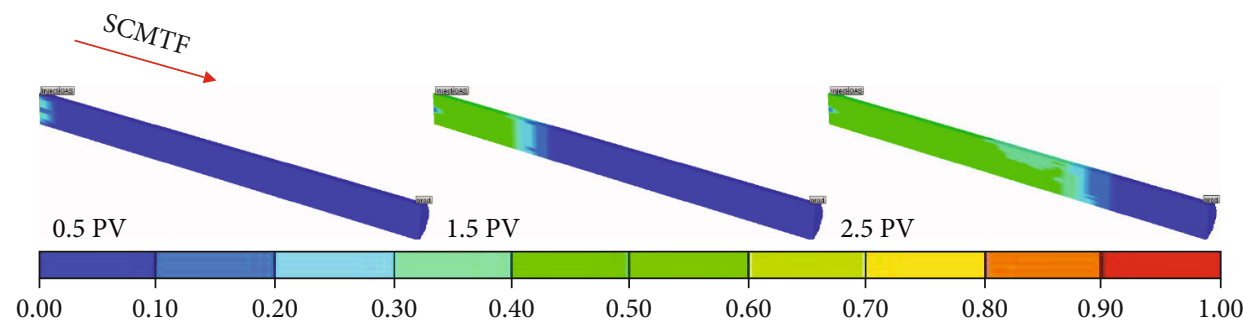

(b)

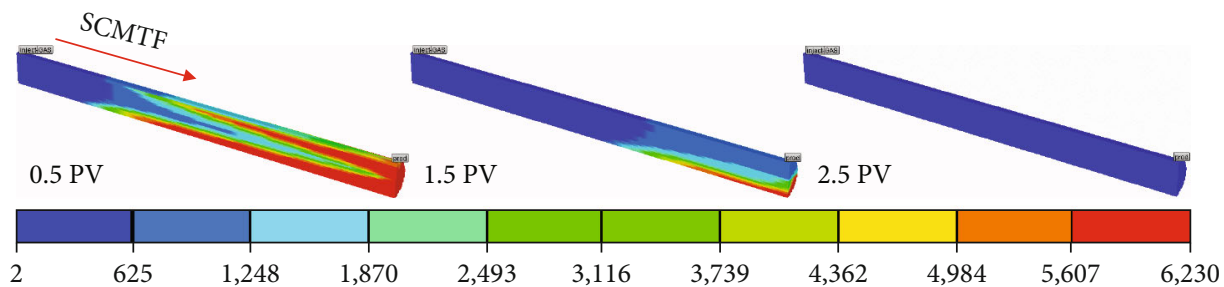

(c)

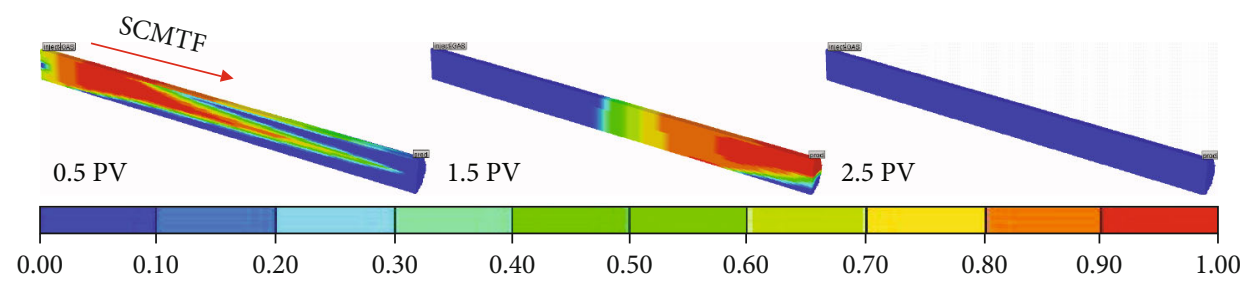

(d)

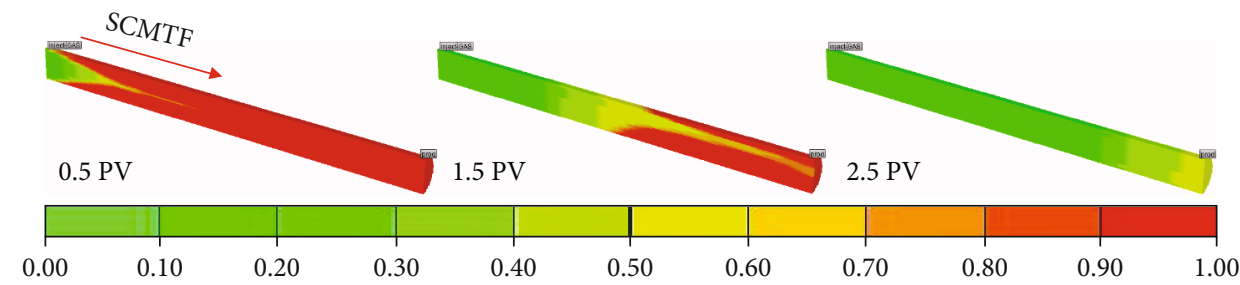

(e)

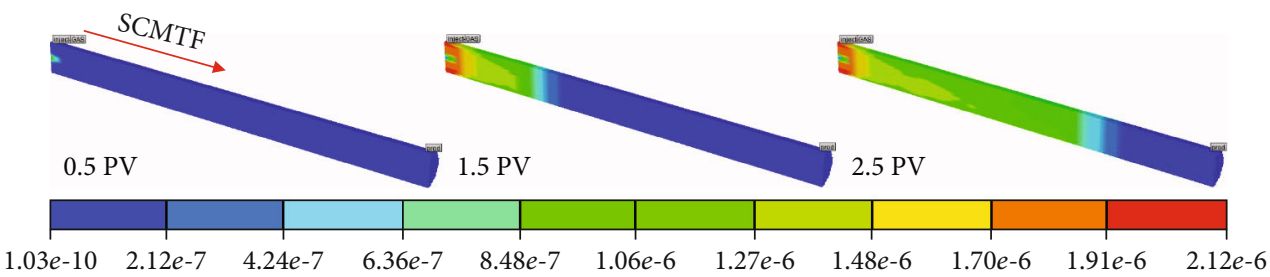

(f)

FIGURE 7: The profiles of SCMTF flooding simulation results: (a) SCW mole fraction distributions; (b) light oil mole fraction distributions; (c) $\mathrm{ScN}_{2}$ and $\mathrm{scCO}_{2}$ mole fraction distributions; (d) viscosity distributions; (e) oil saturation distributions; (f) coke concentration distributions.

(Figure 7(c)). Therefore, the oil viscosity at the upside of the model was lower (Figure $7(\mathrm{~d})$ ), contributing to a lower oil saturation at the upper part (Figure $7(\mathrm{e}))$.
After the SCMTF was injected 2.5 PV, the SCMTF had broken through and a stable channeling path was formed (Figures 7(a) and 7(c)). Therefore, heavy oil was not effectively 


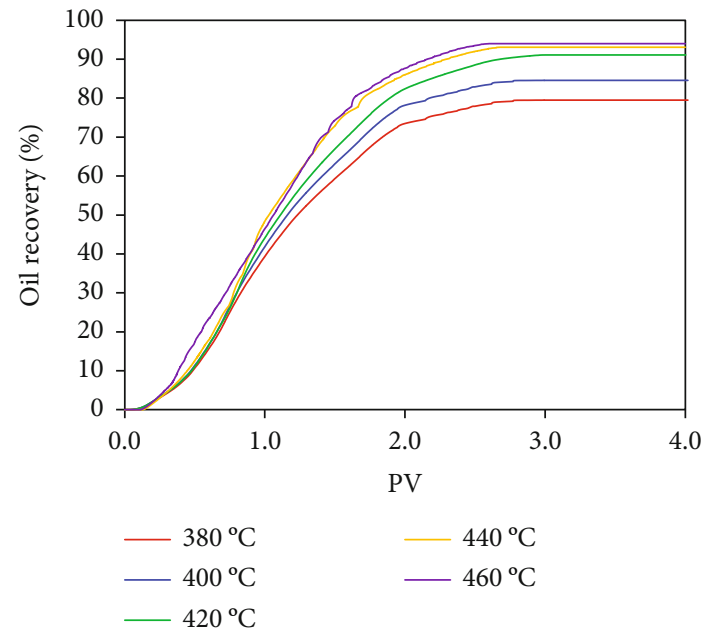

(a)

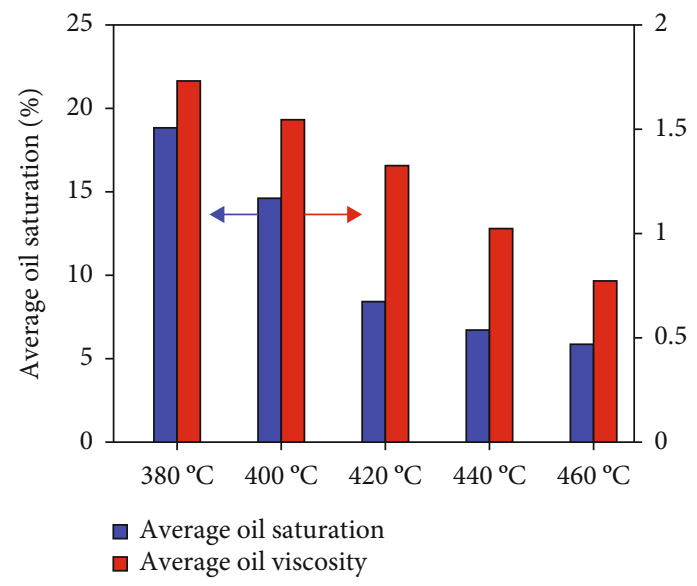

(c)

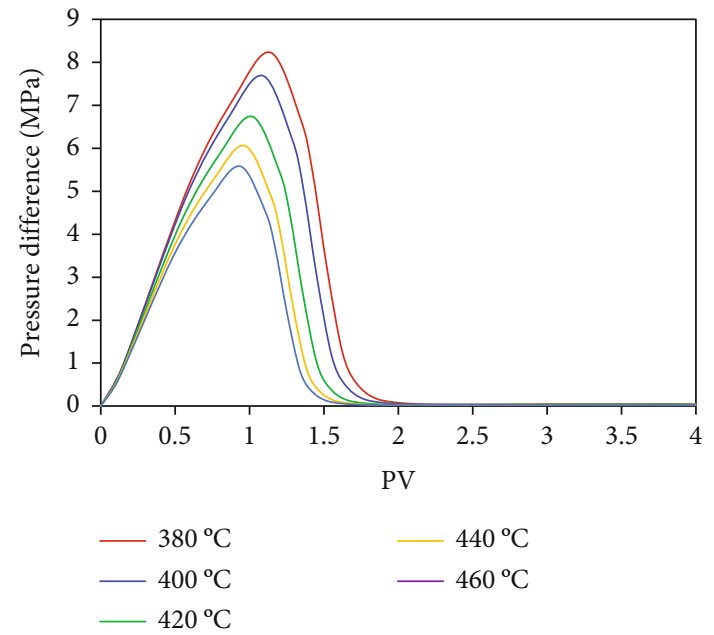

(b)

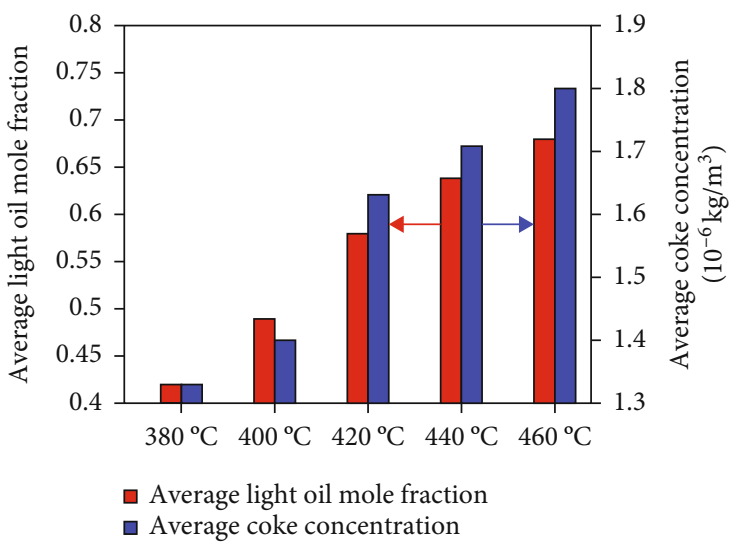

(d)

FIGURE 8: Comparison of simulation results of SCMTF flooding at different temperatures: (a) oil recovery; (b) pressure difference; (c) average oil viscosity and oil saturation; (d) average light oil mole fraction and coke concentration.

displaced by SCMTF (Figure 7(e)). At the end of SCMTF flooding, the average residual oil saturation was $18.76 \%$.

The formation of coke was determined by the pyrolysis reaction, which was deeply affected by the temperature. Therefore, coke mainly deposited near the inlet, and the coke distribution was extended with the continuous injection of SCMTF (Figure 7(f)). However, the SCMTF was proved to suppress the coke formation. Thus, the highest coke concentration was only $2.46 \times 10^{-6} \mathrm{~kg} / \mathrm{cm}^{3}$ at the end of flooding, which was relatively low and might do limited damage on formation.

\subsubsection{The Effects of Operation Parameters on SCMTF Flooding}

(1) The effect of injection temperature

The effect of injection temperature on SCMTF flooding performance was investigated through simulating the SCMTF flooding process at five different cases $\left(380^{\circ} \mathrm{C}, 400^{\circ} \mathrm{C}, 420^{\circ} \mathrm{C}\right.$, $440^{\circ} \mathrm{C}$, and $460^{\circ} \mathrm{C}$, respectively). The results are exhibited in
Figure 8. As presented in Figure 8(a), a remarkable increase from $79.49 \%$ to $93.99 \%$ in oil recovery and a significant decrease in pressure difference (Figure $8(\mathrm{~b})$ ) can be found as the injection temperature varied from $380^{\circ} \mathrm{C}$ to $460^{\circ} \mathrm{C}$.

The main reason for the enhanced oil recovery and reduced pressure difference is that the oil viscosity was reduced with the increasing injection temperatures (Figure 8(c)). The increase in injection temperature could enhance the heat transmission, resulting in a decrease in viscosity. In addition, the increase in injection temperature could considerably intensify the heavy oil upgrading in SCMTF [24]. Therefore, the light oil mole fraction increased (Figure $8(\mathrm{~d})$ ), leading to a further decrease in oil viscosity.

The coke formation was also significantly enhanced with the increase in temperatures; therefore, the average coke concentration (Figure $8(\mathrm{~d})$ ) was increased from $1.33 \times 10^{-6}$ to $1.8 \times 10^{-6} \mathrm{~kg} / \mathrm{cm}^{3}$, suggesting that a substantial increase in injection temperature may induce a potential damage on formation. Thus, the injection temperature should be limited in a reasonable range. 


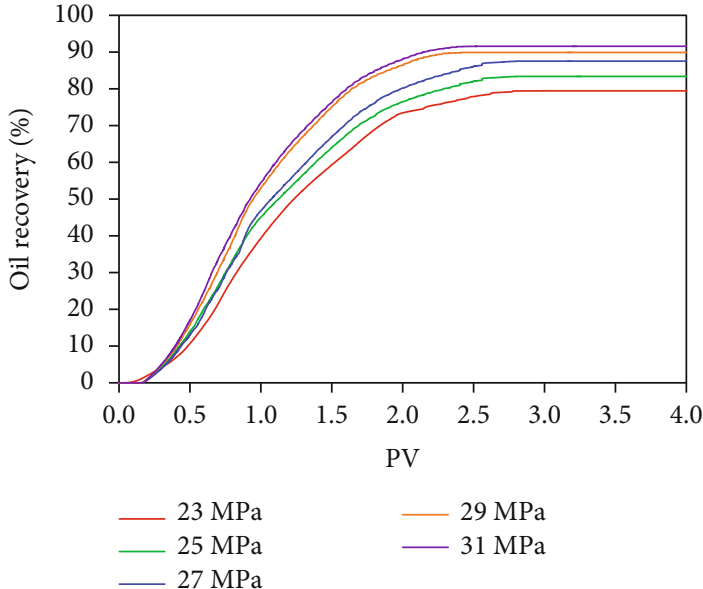

(a)

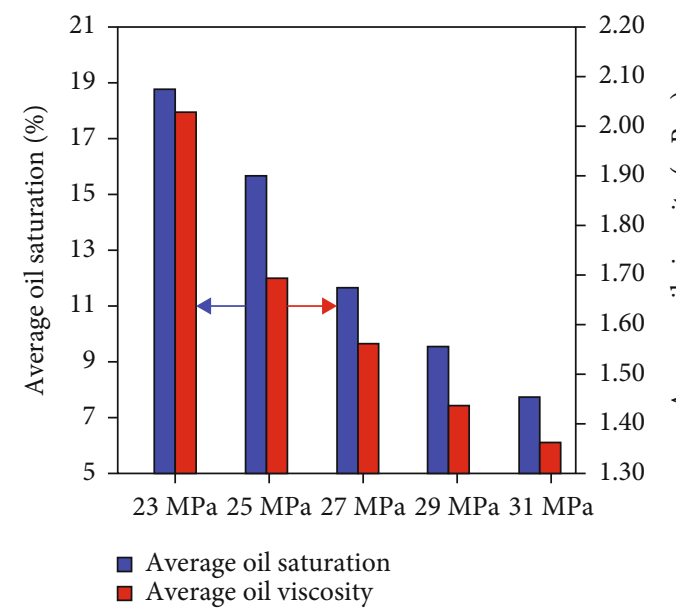

(c)

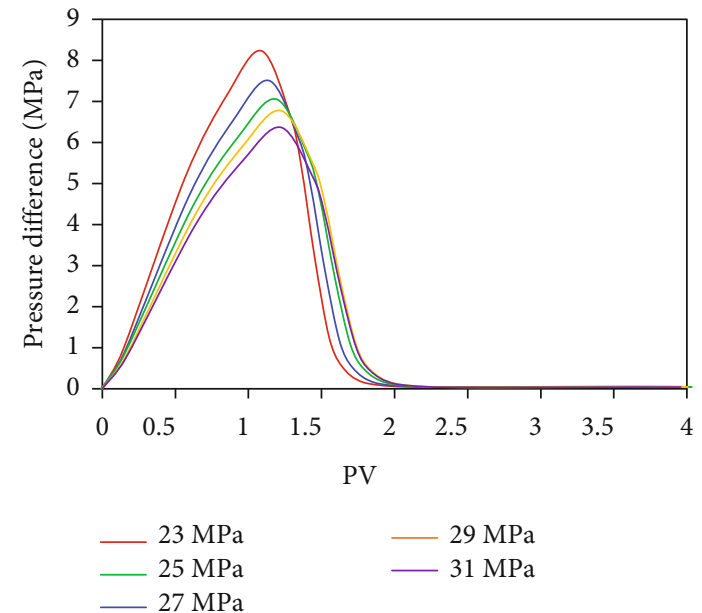

(b)

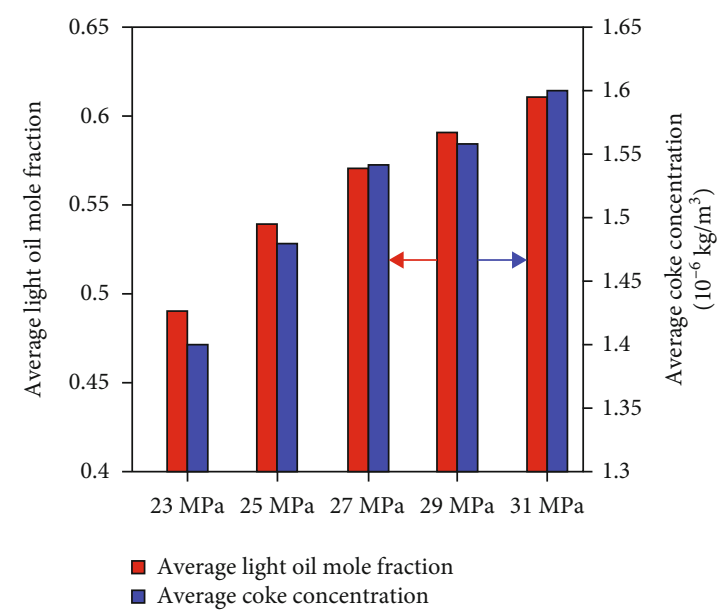

(d)

FIGURE 9: Comparison of SCMTF flooding at different pressures: (a) oil recovery; (b) pressure difference; (c) average oil saturation and oil viscosity; (d) average light oil mole fraction and coke concentration.

(2) The effect of injection pressure

Different injection pressures (23 $\mathrm{MPa}, 25 \mathrm{MPa}, 27 \mathrm{MPa}$, $29 \mathrm{MPa}$, and $31 \mathrm{MPa}$ ) were assigned to study their effects on the performance of SCMTF flooding. The performances of SCMTF flooding considering different injection pressures are presented in Figure 9. As presented in Figure 9(a), the oil recovery increases from $79.49 \%$ to $91.62 \%$ with the injection pressure rising from $23 \mathrm{MPa}$ to $31 \mathrm{MPa}$.

As exhibited, the pressure difference (Figure 9(b)) and oil viscosity (Figure 9(c)) were reduced with pressure increasing. This should be ascribed to two reasons: first, during the flooding process, the dissolution of $\mathrm{scN}_{2}$ and $\mathrm{scCO}_{2}$ was enhanced at rising pressure, which could increase oil mobility. Second, the increase in injection pressure can intensify the upgrading of heavy oil in SCMTF [24]. Therefore, the light oil mole fraction was increased in the model (Figure 9(d)).

Moreover, the high pressure difference period was lengthened at rising pressures (Figure 9(b)), suggesting that the increasing pressure mitigated the override phenomena.
This should be ascribed to the fact that the density of SCMTF increases as the pressure increases, thus suppressing override by reducing density difference between SCMTF and heavy oil. As a result, the mitigated SCMTF override and increased oil mobility resulted in a lower oil saturation (Figure 9(c)), indicating that increasing injection pressure is of benefit to improve heavy oil production.

(3) The effect of $\mathrm{scN}_{2}$ and $\mathrm{scCO}_{2}$ mixture

Simulation schemes with five different mole ratios of $\mathrm{scN}_{2}$ and $\mathrm{scCO}_{2}$ mixture to SCW $(0: 5,0.5: 5,1: 5,1.5: 5$, and 2:5) were conducted to explore the effects of $\mathrm{scN}_{2}$ and $\mathrm{ScCO}_{2}$ injection rates on SCMTF flooding. The results are displayed in Figure 10. As illustrated in Figure 10(a), the oil recovery is significantly increased from $70.26 \%$ to $81.56 \%$ as the mole ratio of $\mathrm{scN}_{2}$ and $\mathrm{scCO}_{2}$ mixture to SCW rises from $0: 5$ to $1: 5$, whereas the increase in mole ratio from 1 $: 5$ to $2: 5$ only slightly improves the oil recovery from $79.49 \%$ to $81.56 \%$. 


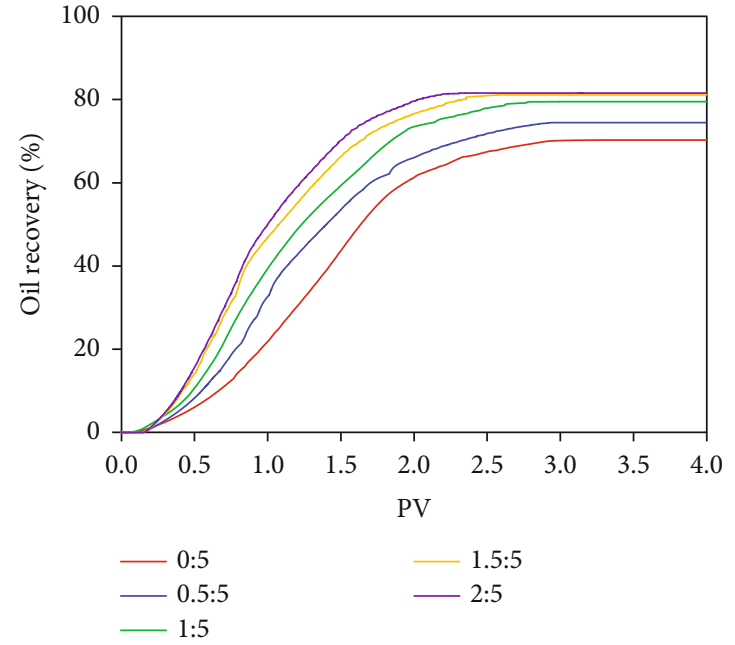

(a)

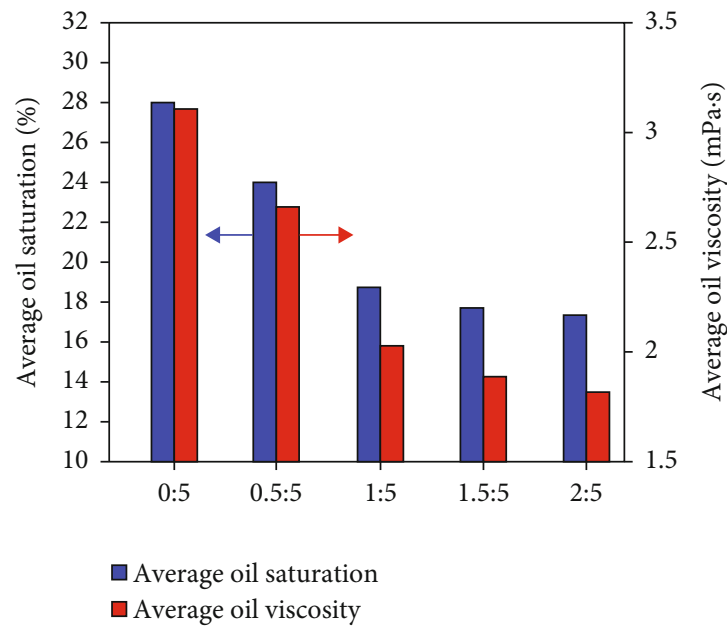

(c)

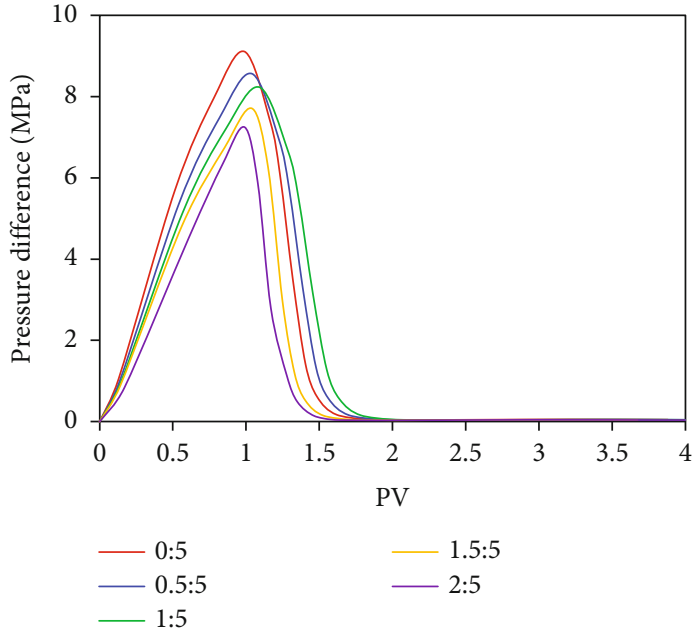

(b)

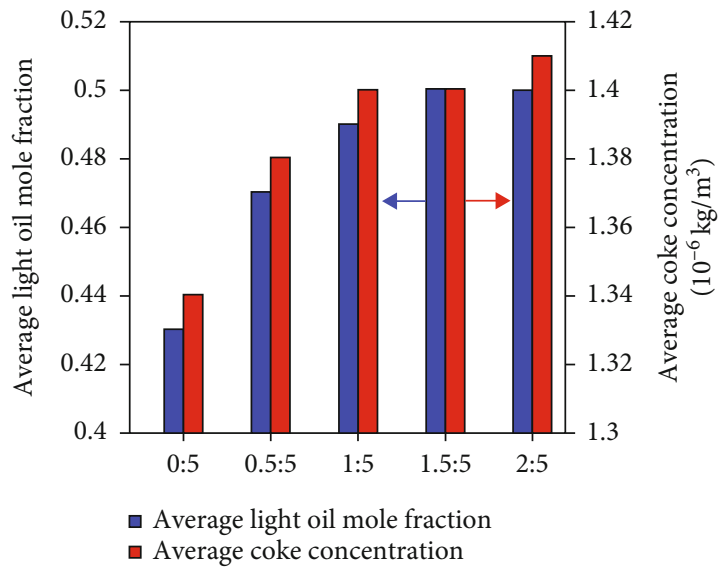

(d)

FIGURE 10: Comparison of SCMTF flooding at different $\mathrm{scN}_{2}$ and $\mathrm{scCO}_{2}$ injection rates: (a) oil recovery; (b) pressure difference; (c) average oil saturation and oil viscosity; (d) average light oil mole fraction and coke concentration.

This is because, with the increase in the mole ratio of $\mathrm{scN}_{2}$ and $\mathrm{scCO}_{2}$ mixture to SCW from $0: 5$ to $1: 5$, the dissolution of $\mathrm{scN}_{2}$ and $\mathrm{scCO}_{2}$ in heavy oil was significantly enhanced, and the upgrading of heavy oil would also be accelerated [24]. As a consequence, the oil mobility was increased (Figure 10(c)), contributing to a more rapid oil production (Figure 10(a)). However, when the mole ratio of $\mathrm{scN}_{2}$ and $\mathrm{scCO}_{2}$ mixture to SCW increased from 1:5 to 2: 5 , the increase of $\mathrm{scN}_{2}$ and $\mathrm{scCO}_{2}$ solubility in heavy oil was limited. The additional $\mathrm{scN}_{2}$ and $\mathrm{scCO}_{2}$ cannot effectively decrease oil viscosity (Figure 10(c)), and the excess of the $\mathrm{scN}_{2}$ and $\mathrm{scCO}_{2}$ injection rate resulted in an early breakthrough of SCMTF (Figure 10(b)), which was adverse to the oil production at the late stage. In addition, after the mole ratio of $\mathrm{scN}_{2}$ and $\mathrm{scCO}_{2}$ mixture to SCW exceeds $1: 5$, the increase in the mole ratio of $\mathrm{scN}_{2}$ and $\mathrm{scCO}_{2}$ mixture to SCW had no obvious influence on heavy oil upgrading (Figure 10(d)). Therefore, the oil viscosity varied slightly at the end of flooding with the increase in mole ratio from 1 : 5 to $2: 5$ (Figure 10(c)).
Consequently, the residual oil saturation decreased significantly with the rise of the mole ratio of $\mathrm{scN}_{2}$ and $\mathrm{scCO}_{2}$ mixture to SCW from $0: 5$ to $1: 5$ and almost remained constant as the mole ratio increased from $1: 5$ to $2: 5$ (Figure 10(c)), suggesting that a moderate ratio of the $\mathrm{scN}_{2}$ and $\mathrm{scCO}_{2}$ in SCMTF would be economic and efficient during SCMTF injection.

3.2. Field-Scale Numerical Simulation. To investigate the performance of SCMTF flooding on deep offshore oil fields, a deep offshore oil reservoir located in Bohai Bay, China (Figure 11), was selected as the object of study. The model consisted of $69 \times 64 \times 10=44160$ grids. The grid size in the $I$ and $J$ directions was $30 \mathrm{~m}$, and the grid thickness varied from $0.25-2.19 \mathrm{~m}$.

The distributions of porosity and permeability are displayed in Figures 11(b) and 11(c). The average porosity and permeability were $24.44 \%$ and $1096 \mathrm{mD}$, respectively. In addition, the component, fluid, and reaction models and 


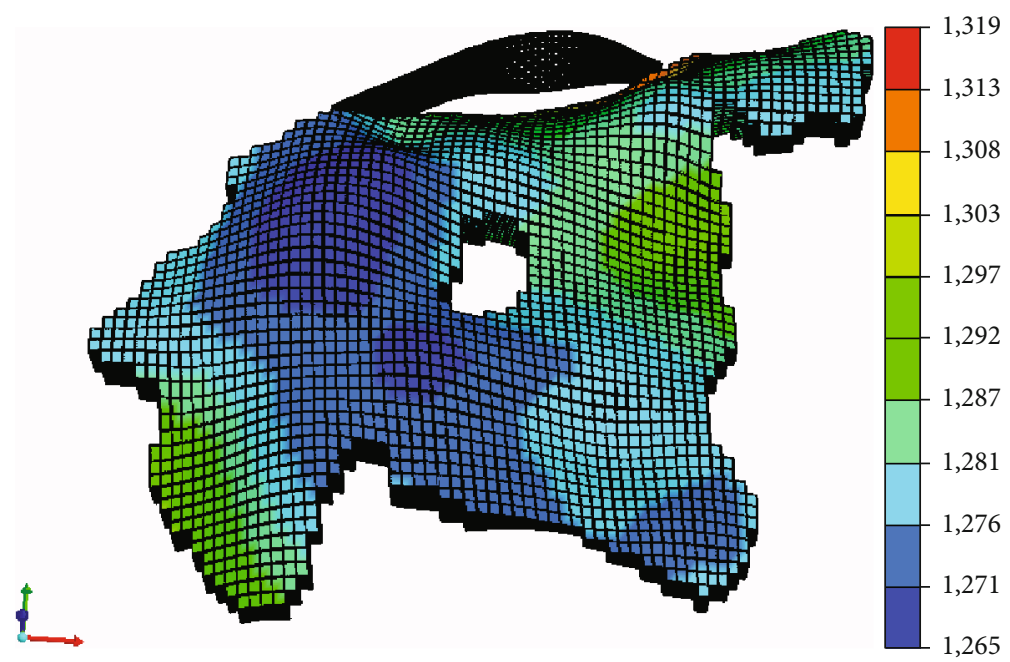

(a)

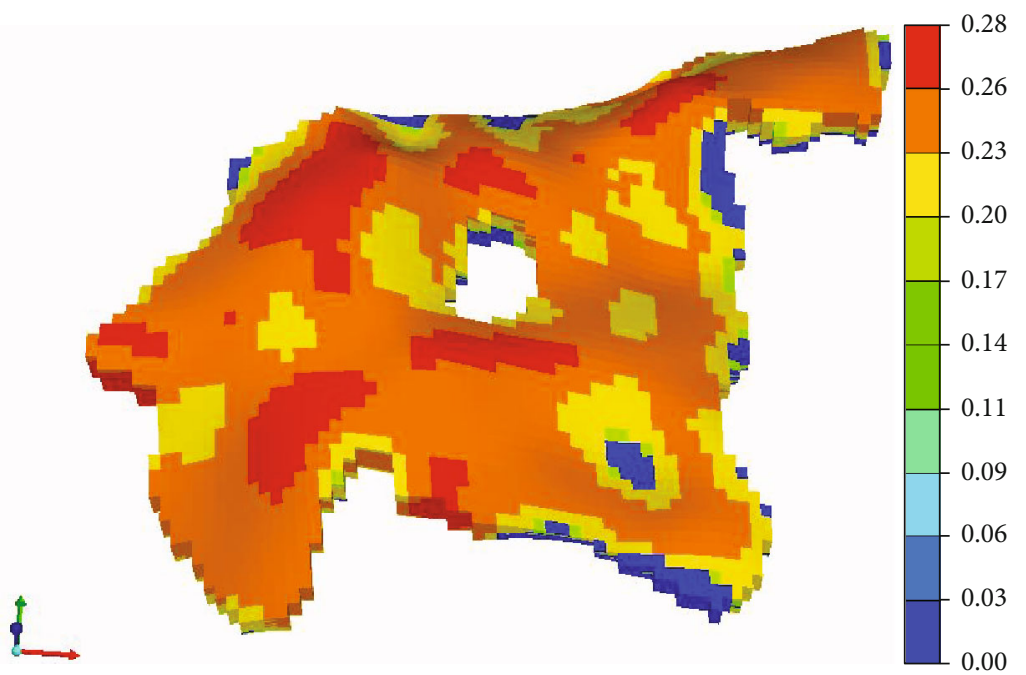

(b)

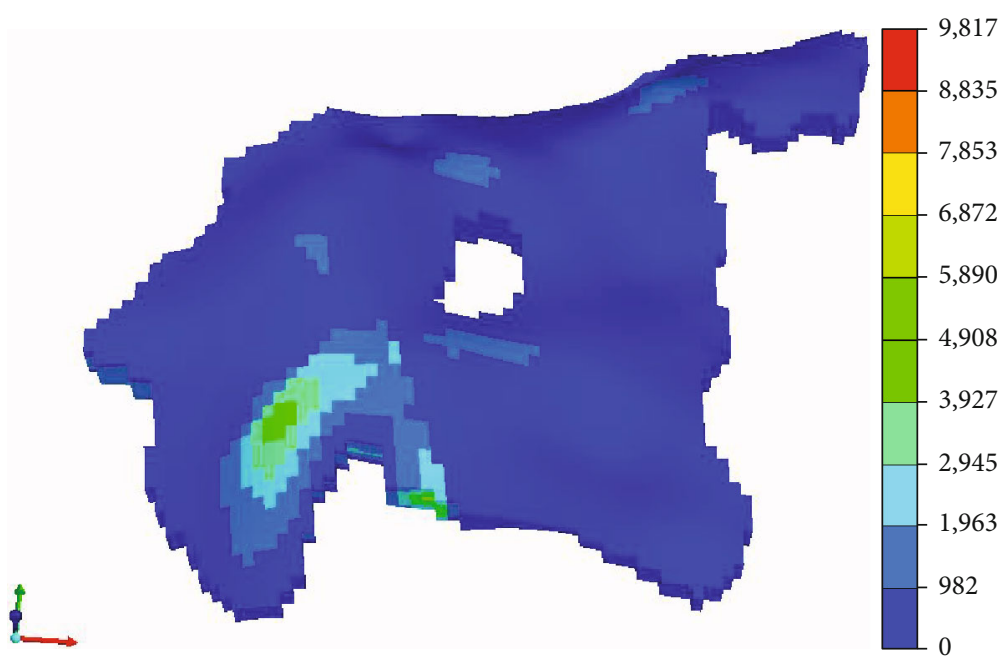

(c)

FIGURE 11: Oil reservoir model: (a) grid top; (b) porosity distribution; (c) permeability distribution. 

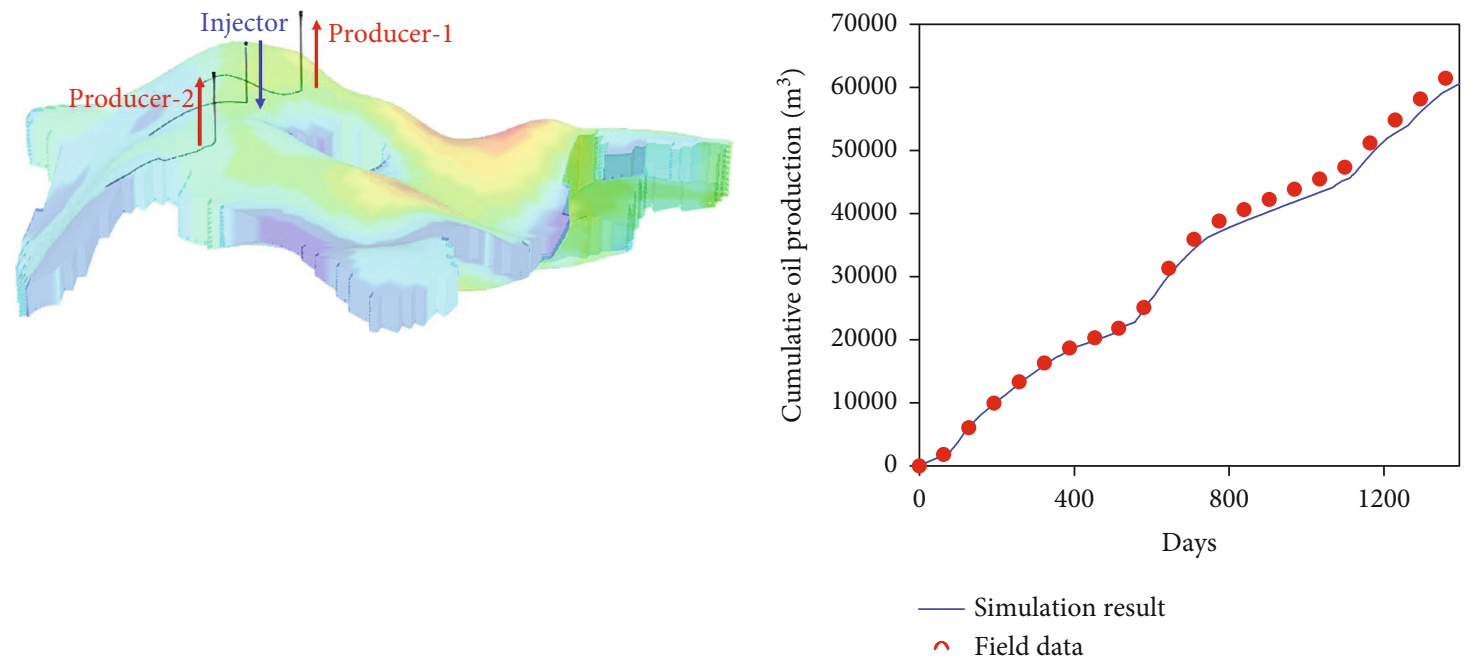

(a)

(b)

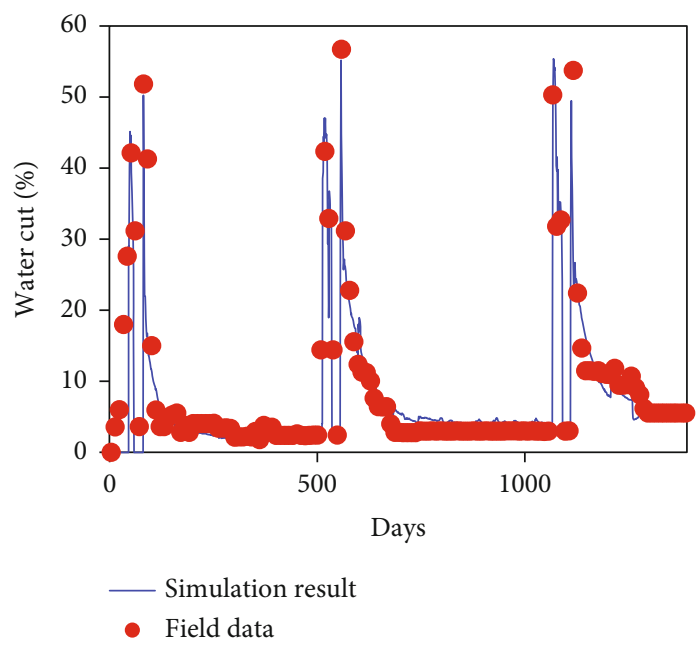

(c)

FIGURE 12: Well trajectories and history matching results: (a) well trajectories; (b) cumulative oil production; (c) water cut.

other key properties were obtained from the matched labscale numerical model.

The reservoir model contained two horizontal wells (Figure 12(a)), respectively. The history match result of two wells is exhibited in Figure 12, indicating that the model could accurately simulate the oil production performance of practical reservoir.

To simulate the SCMTF flooding process, a new injector was drilled between the two horizontal wells (Figure 11(c)). The SCMTF was injected at $380^{\circ} \mathrm{C}$ and $23 \mathrm{MPa}$, and a surface fluid rate of $240 \mathrm{~m}^{3} / \mathrm{d}$ and a mole ratio of SCW : $\mathrm{scN}_{2}: \mathrm{scC}$ $\mathrm{O}_{2}=500: 85: 15$ (consistent with the experiment) was adapted as the SCMTF injection rate. To evaluate the feasibility of SCMTF on the practical offshore heavy oil reservoir, a steam flooding simulation $\left(320^{\circ} \mathrm{C}, 17 \mathrm{MPa}\right.$, steam quality 0.4 , and a surface water rate of $240 \mathrm{~m}^{3} / \mathrm{d}$ ) was also performed for comparison. A production-injection ratio of 1.2 was employed for both of simulation runs. The simulation of flooding was started at the end of field history and lasted for 8030 days. The results are listed in Figures 13-17.

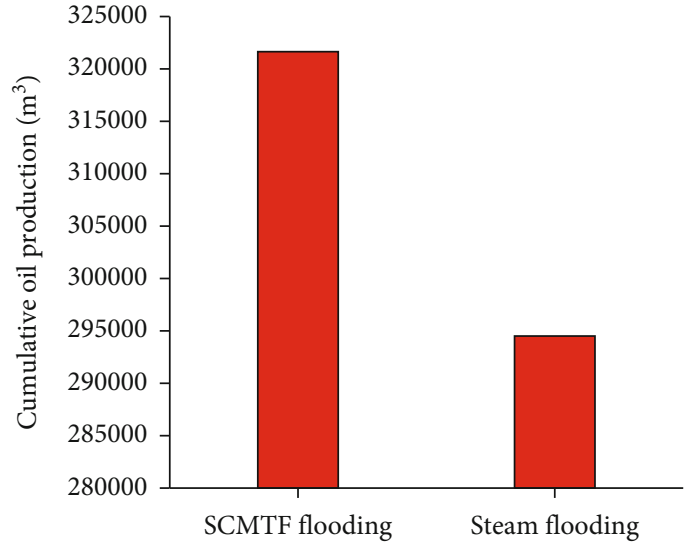

FIGURE 13: Cumulative oil production of different thermal methods.

As shown in the cumulative oil production results (Figure 13), the injection of SCMTF significantly enhances the oil production performance as compared to steam 


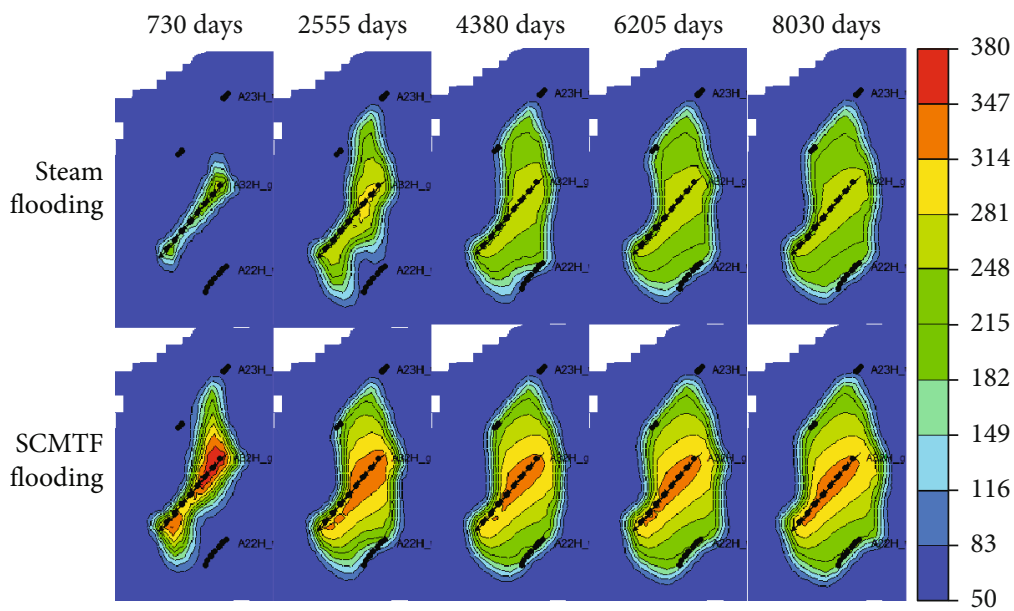

(a)

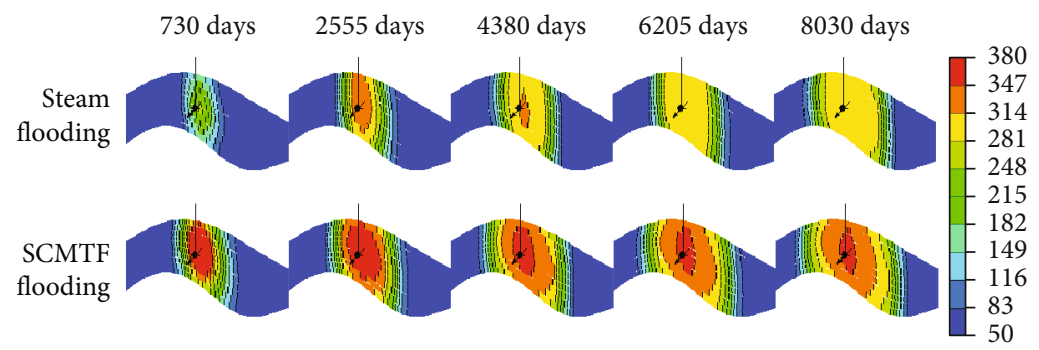

(b)

FIGURE 14: Comparison of heating areas of steam and SCMTF flooding: (a) horizon direction; (b) vertical direction.

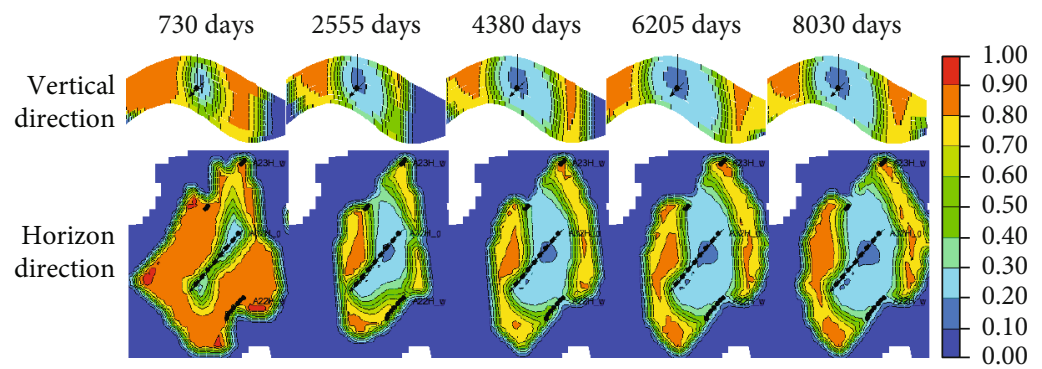

FIGURE 15: The mole fraction distribution of $\mathrm{scN}_{2}$ and $\mathrm{scCO}_{2}$ mixture during SCMTF flooding.

injection (the cumulative oil production increased by 27122 $\mathrm{m}^{3}$ ), demonstrating that the SCMTF is feasible in deep offshore heavy oil recovery.

The temperature fields (Figure 14) show that the SCMTF could effectively expand the heating area in comparison to steam. This is because the injected $\mathrm{scN}_{2}$ and $\mathrm{scCO}_{2}$ accumulated at the top of reservoir (Figure 15) and reduced the heat loss of thermal agent to the overburden. Moreover, as aforementioned, $\mathrm{scN}_{2}$ and $\mathrm{scCO}_{2}$ mitigated the SCW override, which enhanced the promotion of thermal agent chamber at horizon direction (Figure 14(b)). In addition, the injection temperature of SCMTF was much higher than steam, resulting in an enhanced heat transfer.

Furthermore, compared to steam flooding, the rapid promotion (Figure 14(a)) and dissolution of injected
$\mathrm{scN}_{2}$ and $\mathrm{scCO}_{2}$ during SCMTF flooding further expanded the low oil viscosity zone (Figure 16(a)). Additionally, the SCMTF injection induced the heavy oil upgrading, which further increased the oil mobility (Figure 17). The factors mentioned above led to a considerably extended the oil drainage area (Figure 16(b)) as compared to steam flooding. As a result, the average residual oil saturation decreased from $67 \%$ in steam flooding to $62 \%$ in SCMTF flooding.

Notably, the coke mainly deposited near the injector, and its concentration increased with the continuous SCMTF injection (Figure 17), which is in accordance with the labscale simulations. However, the SCMTF can suppress coke formation. Therefore, the coke deposition was not severe, which may not lead to a formation damage. 


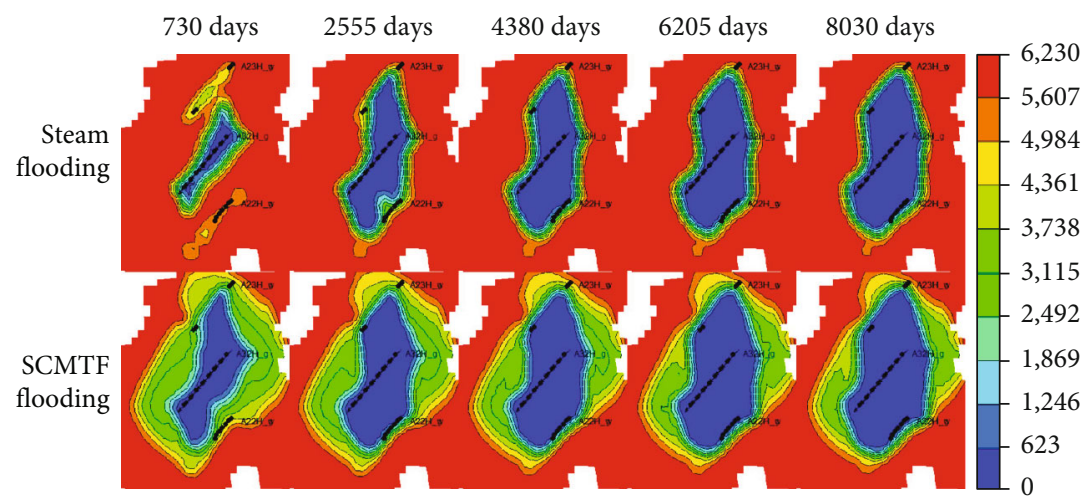

(a)

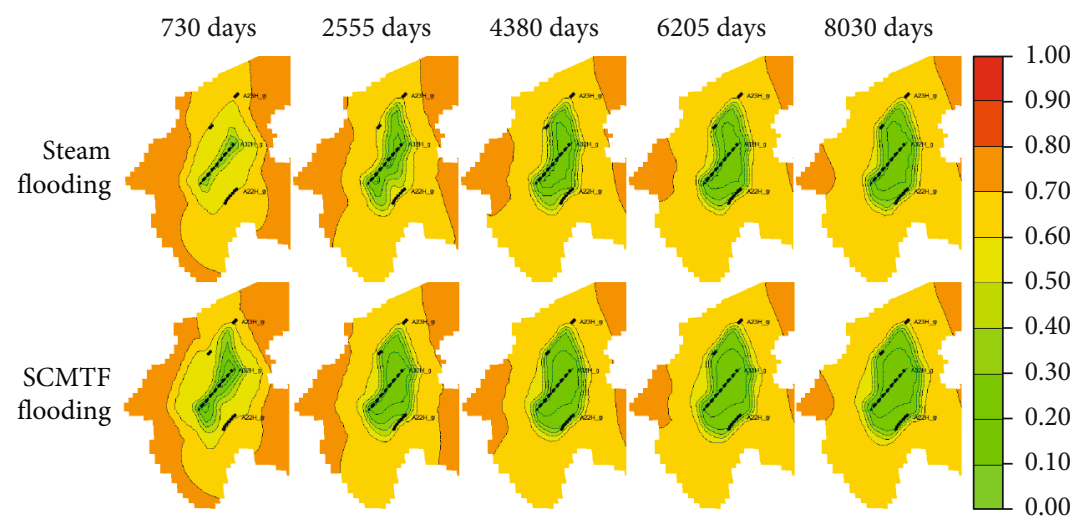

(b)

FIGURE 16: Comparison of viscosity and residual oil saturation during steam and SCMTF flooding: (a) oil viscosity distribution; (b) residual oil saturation distribution.
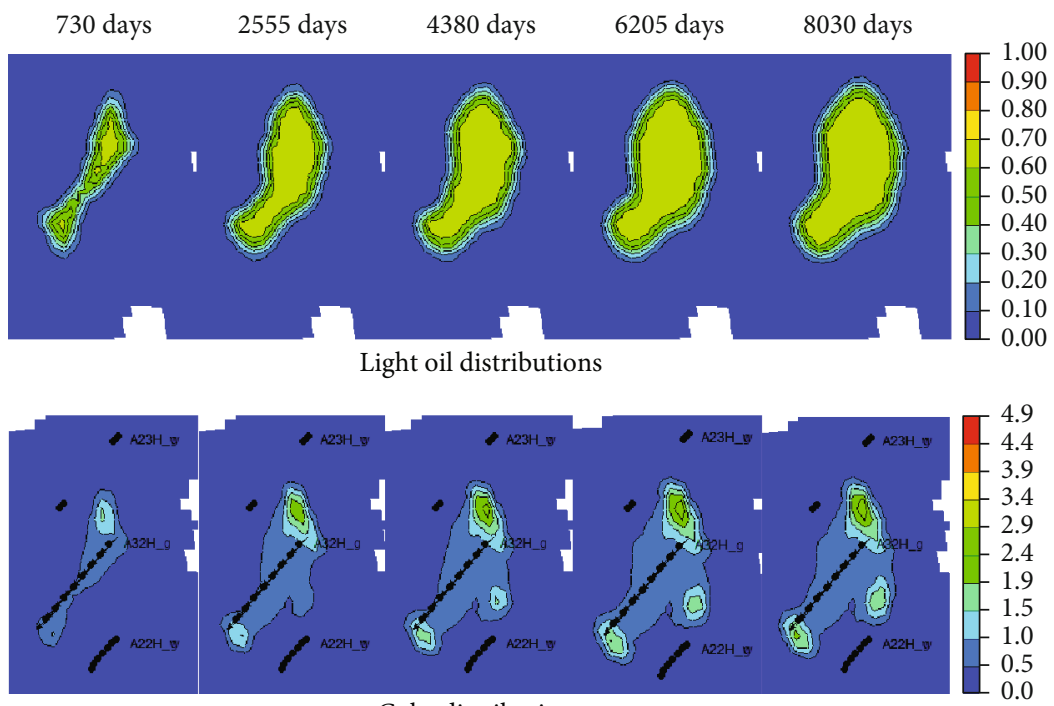

Coke distributions

FIGURE 17: Light oil mole fraction and coke concentration distributions of SCMTF flooding.

\section{Conclusions}

(1) The experimental results of the sandpack flooding showed that, in contrast of steam and SCW flooding, SCMTF flooding can give the highest oil recovery of
$80.89 \%$, which is $29.60 \%$ higher than that of the steam flooding and $11.09 \%$ higher than that of SCW flooding. The field-scale simulation indicated that the SCMTF flooding increased oil production by $27122 \mathrm{~m}^{3}$ in comparison to steam flooding. 
Therefore, the SCMTF is feasible in improving deep offshore heavy oil recovery

(2) The history matching process illustrates average errors of $3.24 \%$ in oil recovery and of $4.33 \%$ in pressure difference, confirming that the developed numerical model can precisely simulate the dynamic of SCMTF flooding

(3) During SCMTF processes, the dissolution of gas in heavy oil played a leading role in oil viscosity reduction at the initial stage of flooding. With the flooding proceeding to middle stage, the synthesis effects of the heating, heavy oil upgrading, and gas dissolution resulted in a rapid decrease in oil saturation. After SCMTF broke through, the heavy oil could not be extracted effectively

(4) An increase in injection temperature benefits the oil production performance. However, too much increase in injection temperature leads to damage formation. Thus, a reasonable injection temperature should be adapted during SCMTF flooding

(5) The rise of injection pressure can increase oil recovery by enhancing the heavy oil upgrading and gas dissolution in heavy oil. Therefore, the SCMTF is suggested to be injected at a pressure as high as the oil field can withstand

(6) Improving the mole ratio of $\mathrm{scN}_{2}$ and $\mathrm{scCO}_{2}$ mixture to SCW benefits oil production. Nevertheless, an excess of $\mathrm{scN}_{2}$ and $\mathrm{scCO}_{2}$ leads to an early breakthrough of SCMTF. Therefore, in SCMTF flooding processes, a moderate ratio of the $\mathrm{scN}_{2}$ and $\mathrm{scCO}_{2}$ mixture is essential for economic performance

\section{Data Availability}

The raw/processed data required to reproduce these findings cannot be shared at this time as the data also forms part of an ongoing study.

\section{Conflicts of Interest}

The authors declare that there is no conflict of interest regarding the publication of this paper.

\section{Acknowledgments}

This research was funded by the Open Fund of State Key Laboratory of Offshore Oil Exploitation (Project No. CCL2018RCPS0017RON) and the China National Offshore Oil Corporation (Project No. YXKY-ZX 06 2021).

\section{References}

[1] X. Sun, Y. Zhang, Z. Gai, H. Zhao, G. Chen, and Z. Song, "Comprehensive experimental study of the interfacial stability of foamy oil and identification of the characteristic responsible for foamy oil formation," Fuel, vol. 238, pp. 514-525, 2019.
[2] X. Sun, Z. Song, L. Cai, Y. Zhang, and P. Li, "Phase behavior of heavy oil-solvent mixture systems under reservoir conditions," Petroleum Science, vol. 17, no. 6, pp. 1683-1698, 2020.

[3] X. Dong, H. Liu, Z. Chen, K. Wu, N. Lu, and Q. Zhang, "Enhanced oil recovery techniques for heavy oil and oilsands reservoirs after steam injection," Applied Energy, vol. 239, pp. 1190-1211, 2019.

[4] W. Zhou, C. Xin, S. Chen, Q. Yu, and K. Wang, "Polymerenhanced foam flooding for improving heavy oil recovery in thin reservoirs," Energy \& Fuels, vol. 34, no. 4, pp. 41164128, 2020.

[5] E. Delamaide and W. Parra Moreno, "Enhanced oil recovery of heavy oil in reservoirs with bottom aquifer," in Paper presented at the SPE Western Regional Meeting, p. 19, Garden Grove, California, USA, 2015.

[6] A. J. Jayasekera and S. G. Goodyear, "The development of heavy oil fields in the United Kingdom Continental Shelf: past, present, and future," SPE Reservoir Evaluation \& Engineering, vol. 3, no. 5, pp. 317-379, 2000.

[7] S. Zhou, Q. Li, X. Lv, Q. Fu, and Y. Liu, "Injection-production system and method for supercritical multi-thermal fluid," $\mathrm{CN}$ Patent CN106640008A, 2017.

[8] X. Sun, J. Cai, X. Li, W. Zheng, T. Wang, and Y. Zhang, "Experimental investigation of a novel method for heavy oil recovery using supercritical multithermal fluid flooding," Applied Thermal Engineering, vol. 185, article 116330, 2021.

[9] H. Qu, J.-H. Gong, X.-C. Tan, P. Q. Yuan, Z. M. Cheng, and W. K. Yuan, "Dissolution of polycyclic aromatic hydrocarbons in subcritical and supercritical water: a molecular dynamics simulation study," Chemical Engineering Science, vol. 195, pp. 958-967, 2019.

[10] T. Zhang, X. Chen, H. Shen, and Z. Da, "Upgrading of Tsingtao vacuum residuum in supercritical water (I): a preliminary phase structure study by molecular dynamics simulations," Energy \& Fuels, vol. 33, no. 5, pp. 3908-3915, 2019.

[11] J. Liu, Y. Xing, Y.-X. Chen, P. Q. Yuan, Z. M. Cheng, and W. K. Yuan, "Visbreaking of heavy oil under supercritical water environment," Industrial \& Engineering Chemistry Research, vol. 57, no. 3, pp. 867-875, 2018.

[12] Y. Liu, F. Bai, C.-C. Zhu, P. Q. Yuan, Z. M. Cheng, and W. K. Yuan, "Upgrading of residual oil in sub- and supercritical water: an experimental study," Fuel Processing Technology, vol. 106, pp. 281-288, 2013.

[13] M. Morimoto, Y. Sugimoto, Y. Saotome, S. Sato, and T. Takanohashi, "Effect of supercritical water on upgrading reaction of oil sand bitumen," Journal of Supercritical Fluids, vol. 55, no. 1, pp. 223-231, 2010.

[14] Q. Zhao, L. Guo, Z. Huang, L. Chen, H. Jin, and Y. Wang, "Experimental investigation on enhanced oil recovery of extra heavy oil by supercritical water flooding," Energy \& Fuels, vol. 32, no. 2, pp. 1685-1692, 2018.

[15] Q. Zhao, L. Guo, Y. Wang, H. Jin, L. Chen, and Z. Huang, "Enhanced oil recovery and in situ upgrading of heavy oil by supercritical water injection," Energy \& Fuels, vol. 34, no. 1, pp. 360-367, 2020.

[16] Q. Zhao, L. Guo, Y. Wang, Z. Huang, L. Chen, and H. Jin, "Thermophysical characteristics of enhanced extra-heavy oil recovery by supercritical water flooding," Journal of Engineering Thermophysics, vol. 41, no. 3, pp. 635-642, 2020.

[17] Q. Yin, H. Huo, P. Huang, C. Wang, D. Wu, and Z. Luo, "Effective use of technology research and application of 
supercritical steam on deep super-heavy oil in Lukeqin oilfield," Oilfield Chemistry, vol. 34, no. 4, pp. 635-641, 2017.

[18] Y. Yang, "The trial and application of supercritical water injection at $35 \mathrm{MPa}$ in Lukeqin oilfield," China Petroleum and Chemical Standard and Quality, vol. 1, pp. 217-218, 2012.

[19] C. Liu, W. Zhang, and J. Yin, "Numerical simulation of phase change regularity of supercritical steam in vertical wellbores by taking Gao 3624 block of Gaosheng oilfield as an example," Petroleum Geology and Engineering, vol. 34, no. 4, pp. 106$111,2020$.

[20] Z. Zhang, Z. Jiang, Y. Chen, Y. Yu, W. Guan, and S. Cui, “The investigation of deep heavy oil recovery by supercritical water injection technique," Petroleum Drilling Techniques, vol. 32, no. 6, pp. 44-46, 2004.

[21] C. Wang, P. Liu, F. Wang, B. Atadurdyyev, and M. Ovluyagulyyev, "Experimental study on effects of $\mathrm{CO}_{2}$ and improving oil recovery for $\mathrm{CO}_{2}$ assisted SAGD in superheavy-oil reservoirs," Journal of Petroleum Science and Engineering, vol. 165, pp. 1073-1080, 2018.

[22] S. Li, Z. Li, and X. Sun, "Effect of flue gas and _n_- hexane on heavy oil properties in steam flooding process," Fuel, vol. 187, pp. 84-93, 2017.

[23] Z. Yuan, P. Liu, S. Zhang, X. Li, L. Shi, and R. Jin, "Experimental study and numerical simulation of nitrogen-assisted SAGD in developing heavy oil reservoirs," Journal of Petroleum Science and Engineering, vol. 162, pp. 325-332, 2018.

[24] X. Sun, X. Li, X. Tan et al., "Pyrolysis of heavy oil in supercritical multi-thermal fluid: an effective recovery agent for heavy oils," Journal of Petroleum Science and Engineering, vol. 196, article 107784, 2021.

[25] D. Zhang, Z. Ren, D. Wang, and K. Lu, "Upgrading of crude oil in supercritical water: a five-lumped kinetic model," Journal of Analytical and Applied Pyrolysis, vol. 123, pp. 56-64, 2017.

[26] X.-C. Tan, Q.-K. Liu, D.-Q. Zhu, P. Q. Yuan, Z. M. Cheng, and W. K. Yuan, "Pyrolysis of heavy oil in the presence of supercritical water: the reaction kinetics in different phases," AICHE Journal, vol. 61, no. 3, pp. 857-866, 2015.

[27] A. Boytsova, N. Kondrasheva, and J. Ancheyta, "Pyrolysis kinetics of heavy oil asphaltenes under steam atmosphere at different pressures," Energy \& Fuels, vol. 32, no. 2, pp. 11321138, 2018.

[28] J. Kang, A. A. Myint, S. Sim, J. Kim, W. B. Kong, and Y. W. Lee, "Kinetics of the upgrading of heavy oil in supercritical methanol," The Journal of Supercritical Fluids, vol. 133, pp. 133-138, 2018.

[29] S. Sim, W. B. Kong, J. Kim, J. Kang, H. S. Lee, and Y. W. Lee, "Kinetics of extra-heavy oil upgrading in supercritical water with and without zinc nitrate using the phase separation kinetic model," The Journal of Supercritical Fluids, vol. 165, article 104961, 2020.

[30] P. Haghighat, L. Carbognani Ortega, and P. Pereira-Almao, "Kinetic study of preoxidized asphaltene hydroprocessing in aqueous phase," Energy \& Fuels, vol. 30, no. 7, pp. 56175629, 2016. 